\title{
Formation of tyrosine radicals in photosystem II under far-red illumination
}

\author{
Nigar Ahmadova $^{1} \cdot$ Fikret Mamedov $^{1}$
}

Received: 8 May 2017 / Accepted: 5 September 2017 / Published online: 18 September 2017

(c) The Author(s) 2017. This article is an open access publication

\begin{abstract}
Photosystem II (PS II) contains two redox-active tyrosine residues on the donor side at symmetrical positions to the primary donor, $\mathrm{P}_{680}$. $\mathrm{Tyr}_{\mathrm{Z}}$, part of the water-oxidizing complex, is a preferential fast electron donor while $\operatorname{Tyr}_{\mathrm{D}}$ is a slow auxiliary donor to $\mathrm{P}_{680}{ }^{+}$. We used PS II membranes from spinach which were depleted of the water oxidation complex (Mn-depleted PS II) to study electron donation from both tyrosines by time-resolved EPR spectroscopy under visible and far-red continuous light and laser flash illumination. Our results show that under both illumination regimes, oxidation of $\mathrm{Tyr}_{\mathrm{D}}$ occurs via equilibrium with $\mathrm{Tyr}_{\mathrm{Z}}{ }^{\bullet}$ at $\mathrm{pH} 4.7$ and 6.3. At $\mathrm{pH} 8.5$ direct $\mathrm{Tyr}_{\mathrm{D}}$ oxidation by $\mathrm{P}_{680}{ }^{+}$ occurs in the majority of the PS II centers. Under continuous far-red light illumination these reactions were less effective but still possible. Different photochemical steps were considered to explain the far-red light-induced electron donation from tyrosines and localization of the primary electron hole $\left(\mathrm{P}_{680}{ }^{+}\right)$on the $\mathrm{Chl}_{\mathrm{D} 1}$ in Mn-depleted PS II after the far-red light-induced charge separation at room temperature is suggested.
\end{abstract}

Keywords Photosystem II · Tyrosine Z and D · Electron transfer · Far-red light

Electronic supplementary material The online version of this article (doi:10.1007/s11120-017-0442-3) contains supplementary material, which is available to authorized users.

Fikret Mamedov

fikret.mamedov@kemi.uu.se

1 Molecular Biomimetics, Department of Chemistry Ångström Laboratory, Uppsala University, Box 523, 75120 Uppsala, Sweden

\author{
Abbreviations \\ Chl Chlorophyll \\ Car Carotenoid \\ DPC Diphenylcarbazide \\ EPR Electron paramagnetic resonance \\ Ferri Potassium ferricyanide $\mathrm{K}_{3}\left[\mathrm{Fe}(\mathrm{CN})_{6}\right]$ \\ PS II Photosystem II \\ Pheo Pheophytin \\ $\mathrm{Q}_{\mathrm{A}}$ and $\mathrm{Q}_{\mathrm{B}}$ Primary and secondary plastoquinone accep- \\ tor in PSII \\ $\mathrm{Tyr}_{\mathrm{Z}} \quad$ Tyrosine 161 on the D1 protein \\ Tris Tris(hydroxymethyl)aminomethane \\ $\operatorname{Tyr}_{\mathrm{D}} \quad$ Tyrosine 160 on the D2 protein
}

\section{Introduction}

Solar energy is successfully utilized by plants, algae, and bacteria in the process called photosynthesis. In oxygenic photosynthesis, solar energy is converted to chemical energy in the form of carbohydrates and $\mathrm{O}_{2}$ is released as a byproduct (Kern and Renger 2007; Renger and Renger 2008; Vinyard et al. 2013). The initial reaction of photosynthesis takes place in photosystem II (PS II), a multicomponent Chl protein complex embedded in the thylakoid membrane of chloroplasts and cyanobacteria. The active PS II complex is made from 25 protein subunits and host a chain of the redoxactive cofactors involved in the key water oxidation reaction and subsequent electron transfer (Umena et al. 2011; Wei et al. 2016). These cofactors are bound by the PS II central core which is composed of the $\mathrm{D}_{1}$ and $\mathrm{D}_{2}$ proteins, the inner pigment-protein antenna complexes CP43 and CP47, Cyt $b_{559}$, and several low molecular weight essential subunits (Danielsson et al. 2006; Umena et al. 2011; Suga et al. 2015). On the luminal side, water-oxidizing complex of 
plants and algae is shielded by three extrinsic proteins $\mathrm{PsbO}$, PsbP, and PsbQ (Bricker et al. 2012).

The sequence of electron transfer reactions leading to the oxidation of water occurs in the following order. After light absorption by antenna, $\mathrm{P}_{680}$ is excited and rapidly loses an electron to the nearby primary electron acceptor Pheo. Reduced $\mathrm{Pheo}^{-}$passes an electron to the bound plastoquinone $Q_{A}$, forming $Q_{A}{ }^{-}$which in turn transfers an electron to $\mathrm{Q}_{\mathrm{B}}$ (Renger and Renger 2008). All these cofactors are single electron carriers while exchangeable plastoquinone $\mathrm{Q}_{\mathrm{B}}$ can accept two electrons and then become double protonated upon reduction. Reduced $\mathrm{Q}_{\mathrm{B}} \mathrm{H}_{2}$ diffuses from the $\mathrm{Q}_{\mathrm{B}}$-pocket and is replaced by another plastoquinol from the membrane PQ pool (Renger and Renger 2008; Barber 2016). On the donor side of PS II, the water-oxidizing complex is composed of $\mathrm{Mn}_{4} \mathrm{CaO}_{5}$ cluster and redox-active tyrosine D1-161 $\left(\mathrm{Tyr}_{\mathrm{Z}}\right)$, and mostly bound by the D1 protein. $\mathrm{P}_{680}{ }^{+}$is a strong oxidant with redox potential of $1.25 \mathrm{~V}$, high enough to drive water oxidation reaction via $\mathrm{Tyr}_{\mathrm{Z}}(\mathrm{Grabolle}$ and Dau 2005; Cardona et al. 2012). Water oxidation occurs at the $\mathrm{Mn}_{4} \mathrm{CaO}_{5}$ cluster which goes through S-cycle to oxidize water to a molecular $\mathrm{O}_{2}$ and four protons by transferring four electrons to $\mathrm{P}_{680}{ }^{+}$via $\mathrm{Tyr}_{\mathrm{Z}}$ (Rappaport et al. 2002; Renger and Renger 2008; Vinyard et al. 2013).

In intact oxygen-evolving PS II $\mathrm{Tyr}_{\mathrm{Z}}{ }^{\bullet}$ oxidation has halftime in nsec- $\mu$ sec range (Brettel et al. 1984; Renger 2012). In the absence of $\mathrm{Mn}_{4} \mathrm{CaO}_{5}$ the half-time became by 2-3 orders of magnitude slower (Babcock and Sauer 1975a; Brettel et al. 1984). PS II contains another redox-active tyrosine D2-160 $\left(\operatorname{Tyr}_{\mathrm{D}}\right)$, which is located symmetrically to $\mathrm{Tyr}_{\mathrm{Z}}$ on the D2 protein (Styring et al. 2012). Contrary to $\operatorname{Tyr}_{\mathrm{Z}}, \operatorname{Tyr}_{\mathrm{D}}{ }^{\bullet}$ is very stable and stays oxidized in the dark for minutes to hours (Babcock and Sauer 1973; Styring and Rutherford 1987; Vass and Styring 1991). Due to the slow oxidation under physiological $\mathrm{pH}, \mathrm{Tyr}_{\mathrm{D}}$ is not competitive to $\mathrm{Tyr}_{\mathrm{Z}}$ as an electron donor to $\mathrm{P} 680^{+}$. However, at elevated $\mathrm{pH}$ with a $\mathrm{pK}_{\mathrm{a}} \sim 7.6, \mathrm{Tyr}_{\mathrm{D}}$ becomes a very efficient donor, with half-times comparable to those seen for $\mathrm{Tyr}_{\mathrm{Z}},\left(t_{1 / 2}=190 \mathrm{~ns}\right)$ (Faller et al. 2001, 2002). The difference in the environment of two tyrosines is the reason for their difference in oxidation kinetics (Umena et al. 2011). $\operatorname{Tyr}_{\mathrm{D}}$ is in relative hydrophobic environment, deeply buried in the protein interior. On the contrary, $\mathrm{Tyr}_{\mathrm{Z}}$ is in more hydrophilic surrounding with a cluster of water molecules nearby (Ferreira et al. 2004; Umena et al. 2011; Suga et al. 2015). Interestingly, $\operatorname{Tyr}_{\mathrm{D}}$ has only a single water molecule nearby which can take two positions (2.6-3.1 and 4.3-4.5 ̊) (Umena et al. 2011; Saito et al. 2013; Suga et al. 2015; Sjöholm et al. 2016; Ahmadova et al. 2017).

The primary donor in PS II, $\mathrm{P}_{680}$ consists of four Chl molecules bound by the D1/D2 heterodimer denoted as $\mathrm{P}_{\mathrm{D} 1}, \mathrm{P}_{\mathrm{D} 2}, \mathrm{Chl}_{\mathrm{D} 1}$, and $\mathrm{Chl}_{\mathrm{D} 2}$, (see Scheme 1). The distance from reaction center Chl $\mathrm{P}_{\mathrm{D} 1}$ and $\mathrm{P}_{\mathrm{D} 2}$ to the $\mathrm{Tyr}_{\mathrm{Z}}$ and $\mathrm{Tyr}_{\mathrm{D}}$,

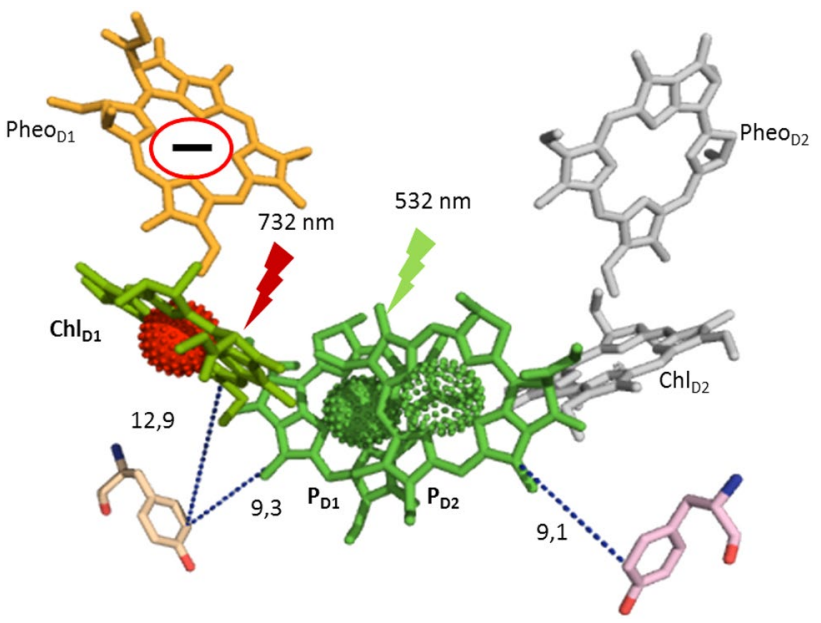

Scheme 1 Electron transfer components and primary charge separation events in PS II under visible and far-red light illumination. Numbers indicate distances between components in $\AA$

respectively is 9.1-9.3 $\AA$. Both tyrosines can be oxidized by $\mathrm{P}_{680}$ entity after light-triggered primary charge separation formed $\mathrm{P}_{680}{ }^{+} \mathrm{Pheo}^{-}$pair. It is still under debate which Chl in $\mathrm{P}_{680}$ entity forms the primary donor (Rappaport and Diner 2008). Interestingly, apart from visible-light-driven charge separation, the far-red light-driven charge separation up to $800 \mathrm{~nm}$ was reported in PS II (Thapper et al. 2009). Taking into account the lower energy of the far-red photons an alternative primary charge separation event was proposed (Thapper et al. 2009). It was also shown that at low temperature the primary charge pair formed under the far-red light illumination is $\mathrm{Chl}_{\mathrm{D} 1}{ }^{+} \mathrm{Pheo}^{-}$(Hughes et al. 2006; Romero et al. 2012; Mokvist et al. 2014; Novoderezhkin et al. 2016). This conclusion was made based on the different yields of the electron donor pathways in PS II at $5 \mathrm{~K}$ (Mokvist et al. 2014). The situation at physiological temperatures is unclear (Reimers et al. 2016).

The slow oxidation behavior of $\operatorname{Tyr}_{\mathrm{D}}$ makes it possible to study by the conventional EPR spectroscopy while $\mathrm{Tyr}_{\mathrm{Z}}$ oxidation kinetics is too fast to be followed. Different biochemical treatment such as Tris and $\mathrm{NH}_{2} \mathrm{OH}$ washing can remove the $\mathrm{Mn}_{4} \mathrm{CaO}_{5}$ cluster and extrinsic proteins, leaving PS II core exposed to the lumen (Boussac and Etienne 1982b; Gadjieva et al. 1999; Mamedov et al. 2007). This makes $\mathrm{Tyr}_{\mathrm{Z}}$ oxidation to slow down by two or three orders of magnitude $\left(\mathrm{t}_{1 / 2}=20-600 \mathrm{~ms}\right)$ (Buser et al. 1990). In this case both tyrosine donors can be accessed by EPR spectroscopy. Symmetrically situated at the different sides of $\mathrm{P}_{680}$, they constitute a useful, simplified system to study the far-redinduced photochemistry at room temperature (Scheme 1).

In the present work we investigate the primary charge separation through oxidation of two tyrosines under two different excitation wavelengths. We have studied tyrosine 
oxidation kinetics in the Mn-depleted PS II membranes at different $\mathrm{pH}$ values. The difference in the oxidation efficiency of $\operatorname{Tyr}_{\mathrm{Z}}$ and $\mathrm{Tyr}_{\mathrm{D}}$ allowed us to suggest localization of the primary electron donor $\mathrm{Chl}$ in $\mathrm{P}_{680}$ after far-red illumination at physiological temperature.

\section{Materials and methods}

\section{Sample preparation}

PS II-enriched membranes (BBY type) were isolated from hydroponically grown spinach (Spinacia oleracea) by the method of Berthold et al. 1981 with some modifications according to Völker et al. (1985). The samples were resuspended in a $25 \mathrm{mM}$ MES buffer, $\mathrm{pH}$ 6.1, $400 \mathrm{mM}$ sucrose, $15 \mathrm{mM} \mathrm{NaCl}$, and $3 \mathrm{mM} \mathrm{MgCl}_{2}$ at a Chl concentration of 5-6 mg/mL and stored at $-80{ }^{\circ} \mathrm{C}$ until use. All sample preparations were performed in darkness or under the dim green light.

The $\mathrm{Mn}_{4} \mathrm{CaO}_{5}$ cluster and extrinsic subunits were removed by the Tris washing (Gadjieva et al. 1999, Mamedov et al. 2007). PS II membranes were resuspended in 1.0 M Tris buffer at $\mathrm{pH} 9.1$ with Chl concentration $1 \mathrm{mg} /$ $\mathrm{mL}$. They were stirred at $4{ }^{\circ} \mathrm{C}$ for $30 \mathrm{~min}$ under room light. After centrifugation, the pellet was washed twice with a low molar buffer containing $2 \mathrm{mM}$ MES-NaOH pH 6.1, $300 \mathrm{mM}$ sucrose, $10 \mathrm{mM} \mathrm{NaCl}, 3 \mathrm{mM} \mathrm{MgCl}_{2}$, and stored at $-80{ }^{\circ} \mathrm{C}$. This treatment washed away $>90 \%$ of bound $\mathrm{Mn}$ and all three extrinsic proteins (Gadjieva et al. 1999). $\operatorname{Tyr}_{\mathrm{D}}$ reduction in Tris-washed PS II samples was obtained by incubation samples at a concentration of $4-5 \mathrm{mg}$ of $\mathrm{Chl} /$ $\mathrm{mL}$ in the dark for $10 \mathrm{~h}$ at room temperature $\left(21^{\circ} \mathrm{C}\right)$. The incubation treatment reduced about $95 \%$ of the $\operatorname{Tyr}_{\mathrm{D}}$ (Fig. 1).

For the experiments samples were diluted to $2 \mathrm{mg} \mathrm{Chl} /$ $\mathrm{mL}$ by addition of the appropriate amount of high molar measuring buffer, containing $300 \mathrm{mM}$ sucrose, $10 \mathrm{mM} \mathrm{NaCl}$, and $3 \mathrm{mM} \mathrm{MgCl}{ }_{2}$ with $150 \mathrm{mM}$ of either glutamic acid (pH

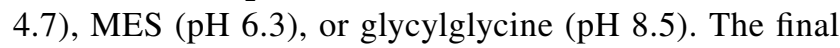
buffer concentration after addition of high molar buffer was $25 \mathrm{mM}$.

Steady-state oxygen evolution activity was measured with a Hansatech Clark-type electrode at $20 \mu \mathrm{g}$ of $\mathrm{Chl} / \mathrm{mL}$ in a measuring buffer at $\mathrm{pH} 6.1 .2 \mathrm{mM}$ potassium ferricyanide $\mathrm{K}_{3}\left[\mathrm{Fe}(\mathrm{CN})_{6}\right]$ and $0.5 \mathrm{mM}$ PpBQ were used as electron acceptors. The activities of the PSII membrane preparation was $\sim 550 \mu \mathrm{mol}$ of $\mathrm{O}_{2} \times(\mathrm{mg} \text { of } \mathrm{Chl})^{-1} \times \mathrm{h}^{-1}(\mathrm{pH} 6.3)$, while Tris-washed samples did not show any oxygen evolution.

\section{EPR measurements}

Room temperature EPR measurements were performed with ELEXSYS E500 spectrometer (Bruker Biospin $\mathrm{GmbH}$ ) equipped with a SuperX bridge and a super high Q SHQE4122 cavity. The measurements were done in a $250 \mu \mathrm{L}$ quartz flat cell at a sample concentration of $\sim 2 \mathrm{mg}$ of $\mathrm{Chl} / \mathrm{mL}$. Steady-state $\mathrm{Tyr}_{\mathrm{Z} / \mathrm{D}}$ oxidation was monitored after induction with LED setup (white or far-red light, see below) mounted at the EPR cavity window at field position of 3465 G. In addition, $\mathrm{Tyr}_{\mathrm{Z} / \mathrm{D}}$ oxidation kinetics was triggered with a $6 \mathrm{~ns}, 100 \mathrm{~mW}, 523$ or $732 \mathrm{~nm}$ laser flash given to the sample. Data analysis was performed with the Bruker Xepr 2.1

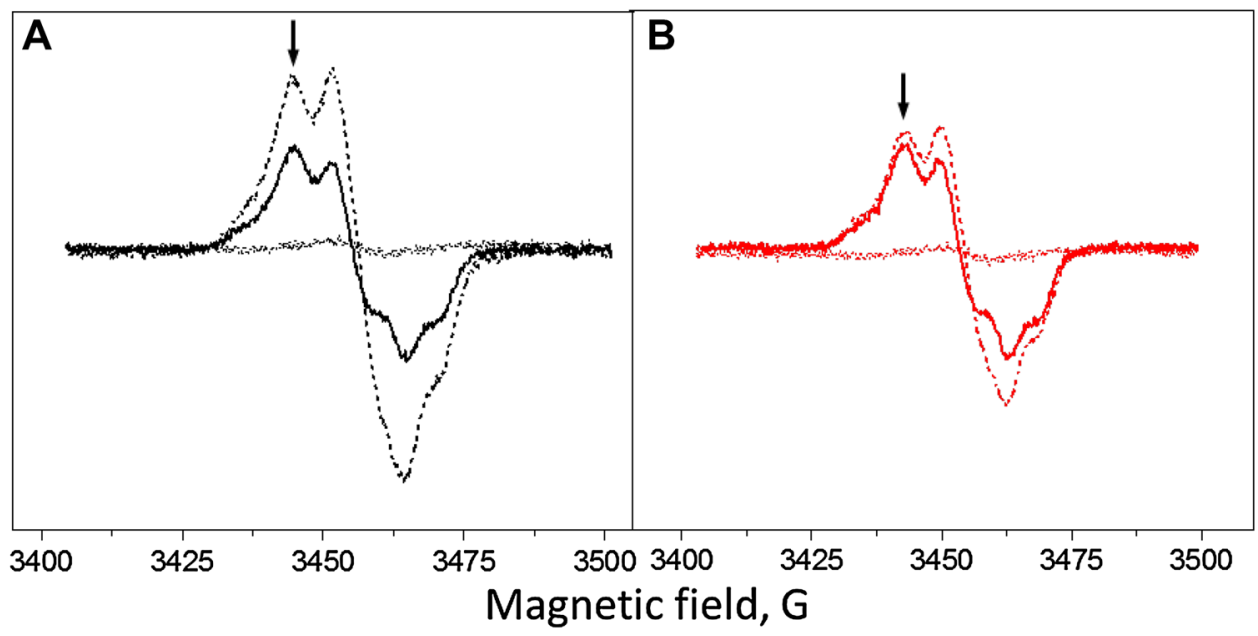

Fig. 1 EPR spectra of the Tyr radicals from the Tris-washed PS II membranes at $\mathrm{pH} 8.5$ induced by white light illumination (A, black spectra) or far-red light illumination (B, red spectra). Spectra shown are after $10 \mathrm{~h}$ dark incubation at room temperature (dotted line spectra), during continuous illumination (dashed line spectra) and after
5 min of dark incubation (solid line spectra). The arrows indicate the field position $(3465 \mathrm{G})$ for the kinetics measurements. EPR conditions: microwave frequency $9.75 \mathrm{GHz}$, microwave power $8 \mathrm{~mW}$, modulation amplitude $5 \mathrm{G}$, temperature $293 \mathrm{~K}$ 
software. The standard error in the signal amplitude estimation in our EPR measurements was less than $5 \%$.

\section{Light sources}

Samples were illuminated with two kinds of LED: white and far-red light. White light LED had one major emission peak at $450 \mathrm{~nm}$ and two smaller peaks at 549 and $600 \mathrm{~nm}$. Far-red light LED had an emission peak at $732 \mathrm{~nm}$. Two cut-off Schott filters CC4 and RG9 were used with far-red LED to ensure no visible-light contamination (see Supplementary Fig. 1S for the actual output spectra of used LED light sources). LEDs were set up at the EPR cavity window. 532 and $732 \mathrm{~nm}$ laser flashes $(20 \mathrm{~mJ}$, pulse duration $6 \mathrm{~ns}$, pulse bandwidth $\pm 0.1 \mathrm{~nm}$ ) were provided by the QuantaRay MOPO-730 optical parametric oscillator, driven by $\mathrm{Nd}$ : YAG laser (Spectra Physics, USA).

\section{Results}

$\operatorname{Tyr}_{\mathrm{D}}{ }^{\bullet}$ is much less stable in the Mn-depleted PS II than in the active PS II samples with the full $\mathrm{O}_{2}$-evolving activity, where reduction of $\operatorname{Tyr}_{\mathrm{D}} \bullet$ requires application of the reducing agents (Vass and Styring 1991; Sjöholm et al. 2016; Ahmadova et al. 2017). The dark incubation of our Triswashed PS II membranes for $10 \mathrm{~h}$ at room temperature resulted in the reduction of $90-95 \%$ of $\operatorname{Tyr}_{\mathrm{D}}{ }^{\bullet}$ (Fig. 1, dotted line spectra). Under illumination, both tyrosines can be observed by the conventional EPR spectroscopy; however, their different kinetic properties allow to clearly distinguish between $\operatorname{Tyr}_{\mathrm{D}}{ }^{\bullet}$ and $\operatorname{Tyr}_{\mathrm{Z}}{ }^{\bullet}$ after light is switched off. Moreover, similar EPR properties of both radicals in the absence of the Mn cluster allow to quantify $\mathrm{Tyr}_{\mathrm{Z}}{ }^{\bullet}$ on the basis of $\operatorname{Tyr}_{\mathrm{D}} \bullet$ radical (Boussac and Etienne 1982a, 1984; Roffey et al. 1994).

Illumination of the sample for 2 min with white light at $\mathrm{pH} 8.5$ and subsequent 5 min dark adaptation resulted in full oxidation of $\operatorname{Tyr}_{\mathrm{D}}{ }^{\bullet}$ (Fig. 1A, solid line spectrum). Any induced $\operatorname{Tyr}_{\mathrm{Z}}{ }^{\bullet}$ has decayed during 5 min of dark adaptation (decay half-time of $\operatorname{Tyr}_{Z}{ }^{\bullet}$ is ca $600 \mathrm{~ms}$ in Tris-washed
PS II at this pH, Table 1) and any decay of $\operatorname{Tyr}_{\mathrm{D}}{ }^{\bullet}$ is negligible. Thus, the resulted spectrum is taken for $100 \%$ of $\operatorname{Tyr}_{\mathrm{D}} \cdot$ and was used in further quantifications. When measurements were performed under illumination conditions, tyrosine radical spectrum arose from $\operatorname{Tyr}_{\mathrm{D}}{ }^{\bullet}(100 \%)$ and the additional intensity, which is attributed to the $\operatorname{Tyr}_{\mathrm{Z}} \bullet$ radical (75\%, Fig. 1A, dashed line spectrum). When measurements were done under far-red illumination, the additional intensity from $\mathrm{Tyr}_{\mathrm{Z}}{ }^{\bullet}$ amounted to only $15 \%$ (Fig. 1B, dashed line spectrum).

The kinetics of $\mathrm{Tyr}_{\mathrm{D}}$ and $\mathrm{Tyr}_{\mathrm{Z}}$ oxidation were measured by monitoring the EPR signal induction at $3465 \mathrm{G}$ (arrow in Fig. 1) under continuous illumination at three different $\mathrm{pH}$ values (Fig. 2). The field position chosen for kinetic measurement is lying outside of the magnetic field range in which signals from Chl and Car cations could contribute (Visser et al. 1977; Hanley et al. 1999).

\section{Tyrosine oxidation under continuous white or far-red light illumination}

Steady-state oxidation of $\mathrm{Tyr}_{\mathrm{D}}$ and $\mathrm{Tyr}_{\mathrm{Z}}$ residues in the Mndepleted PS II membranes under continuous illumination with white or far-red light are shown in Fig. 2. The oxidation kinetics was accelerated towards the higher $\mathrm{pH}$ values under both illumination conditions. The total yield of tyrosine radical formation was also $\mathrm{pH}$ dependent and increased towards high $\mathrm{pH}$. The maximum formation of tyrosine radicals was observed at $\mathrm{pH} 8.5$ (Fig. 2C).

Under white light illumination, the steady-state level of tyrosine oxidation reached maximum at any given $\mathrm{pH}$ quite fast within ca $50 \mathrm{~s}$ (Fig. 2, black traces). The maximum corresponded to $65 \%$ at $\mathrm{pH} 4.7,100 \%$ at $\mathrm{pH} 6.3$, and $195 \%$ at $\mathrm{pH}$ 8.5. Almost $200 \%$ of oxidation indicates that full induction of both $\operatorname{Tyr}_{\mathrm{Z}}{ }^{\bullet}$ and $\operatorname{Tyr}_{\mathrm{D}}{ }^{\bullet}$ was achieved at high $\mathrm{pH}$. Some decay of the steady-state level of the signal was observed during illumination after $50 \mathrm{~s}$ at $\mathrm{pH} 6.3(\sim 5 \%)$ and $100 \mathrm{~s}$ at pH 8.5 ( 10\%) (Fig. 2B, C, black traces). This decay is due to the full reduction of the acceptor side which leads to the backflow of electrons from $\mathrm{Q}_{\mathrm{A}}{ }^{-}$or $\mathrm{Q}_{\mathrm{B}}{ }^{-}$to $\mathrm{Tyr}_{\mathrm{Z}}{ }^{\bullet}$ and/or photoinhibition. Such decay was not observed in the presence

Table 1 Fitted half-times and amplitudes of $\mathrm{Tyr}_{\mathrm{Z}}{ }^{\bullet}$ exponential decay after induction by 532 and 732 nm laser flash in the Tris-washed PSII membranes without any additions or in the presence of $2 \mathrm{mM}$ ferricyanide (Ferri) and $2 \mathrm{mM}$ ferricyanide and $1 \mathrm{mM}$ DPC (Ferri + DPC)

\begin{tabular}{|c|c|c|c|c|c|c|c|c|c|}
\hline \multirow{2}{*}{$\begin{array}{l}\mathrm{t}_{1 / 2}, \mathrm{~ms} \\
\text { (Ampl., \%) }\end{array}$} & \multicolumn{3}{|l|}{$\mathrm{pH} 4.7$} & \multicolumn{3}{|l|}{ pH 6.3} & \multicolumn{3}{|l|}{$\mathrm{pH} 8.5$} \\
\hline & No add. & Ferri & Ferri + DPC & No add. & Ferri & Ferri + DPC & No add. & Ferri & Ferri + DPC \\
\hline $532 \mathrm{~nm}$ & $\begin{array}{c}22 \pm 2 \mathrm{~ms} \\
(34 \%)\end{array}$ & $\begin{array}{c}22 \pm 2 \mathrm{~ms} \\
(85 \%)\end{array}$ & $\begin{array}{c}10 \pm 1.5 \mathrm{~ms} \\
(42 \%)\end{array}$ & $\begin{array}{c}222 \pm 25 \mathrm{~ms} \\
(43 \%)\end{array}$ & $\begin{array}{c}118 \pm 15 \mathrm{~ms} \\
(95 \%)\end{array}$ & $\begin{array}{c}17 \pm 2 \mathrm{~ms} \\
(55 \%)\end{array}$ & $\begin{array}{l}557 \pm 53 \mathrm{~ms} \\
(48 \%)\end{array}$ & $\begin{array}{c}436 \pm 49 \mathrm{~ms} \\
(109 \%)\end{array}$ & $\begin{array}{c}59 \pm 7 \mathrm{~ms} \\
(25 \%)\end{array}$ \\
\hline $732 \mathrm{~nm}$ & $\begin{array}{c}21 \pm 2 \mathrm{~ms} \\
(18 \%)\end{array}$ & $\begin{array}{c}24 \pm 2 \mathrm{~ms} \\
(20 \%)\end{array}$ & $\begin{array}{c}6 \pm 1 \mathrm{~ms} \\
(8 \%)\end{array}$ & $\begin{array}{c}170 \pm 21 \mathrm{~ms} \\
(19 \%)\end{array}$ & $\begin{array}{c}102 \pm 13 \mathrm{~ms} \\
(27 \%)\end{array}$ & $\begin{array}{c}24 \pm 2 \mathrm{~ms} \\
(25 \%)\end{array}$ & $\begin{array}{c}596 \pm 53 \mathrm{~ms} \\
(20 \%)\end{array}$ & $\begin{array}{c}338 \pm 37 \mathrm{~ms} \\
(37 \%)\end{array}$ & $\begin{array}{c}76 \pm 7 \mathrm{~ms} \\
(16 \%)\end{array}$ \\
\hline
\end{tabular}

The standard error in the signal amplitude estimation in our EPR measurements was $<5 \%$ 


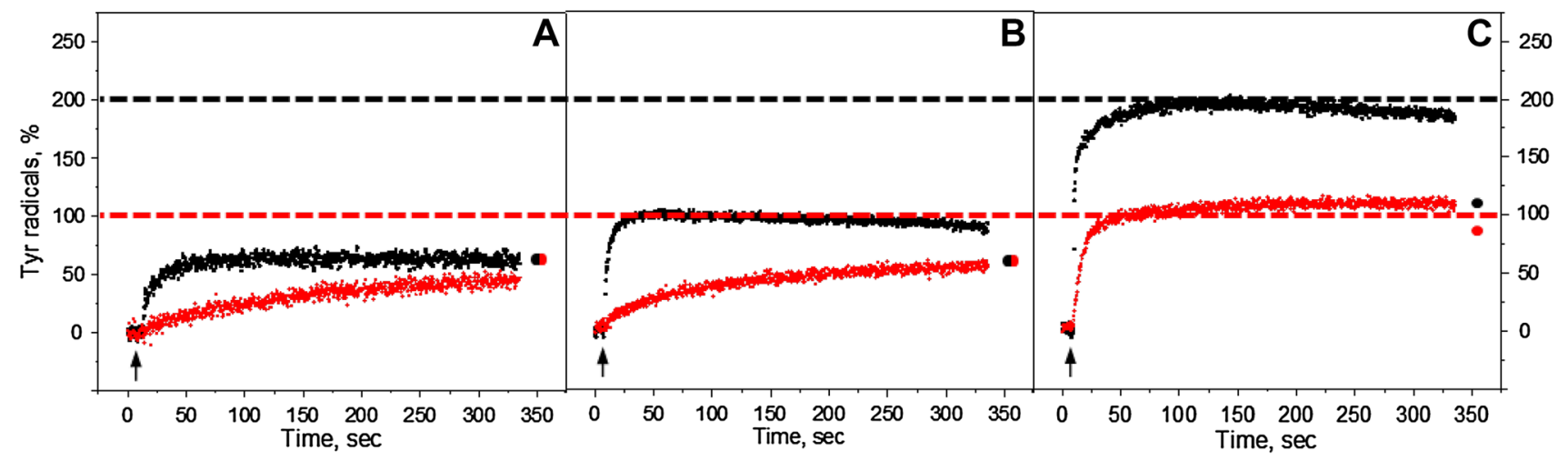

Fig. 2 Kinetics of tyrosine oxidation recorded at $3465 \mathrm{G}$ under continuous white light (black traces) or far-red illumination (red traces) in the reduced Mn-depleted PS II membranes at pH 4.7 (A), $\mathrm{pH} 6.3$ (B), and $\mathrm{pH} 8.5(\mathbf{C})$. Each trace represents an average of four single measurements in independent samples. The amplitude of tyrosine

of exogenous acceptor (see below). Interestingly, after the light was turned off and $5 \mathrm{~min}$ of dark incubation of white light illuminated samples, no decay of tyrosine amplitude was observed at $\mathrm{pH} 4.7$ (Fig. 2A, black dot). While at higher $\mathrm{pH}$, the amplitude of tyrosine signal decreased to $67 \%$ at $\mathrm{pH}$ 6.3 and to $105 \%$ at $\mathrm{pH} 8.5$ (Fig. 2B, C, black dots).

The kinetics of tyrosine oxidation under the far-red illumination was different from the kinetics under the white light illumination at all three $\mathrm{pH}$ values investigated. Oxidation of tyrosine was much slower at $\mathrm{pH} 4.7$ and 6.3 (Fig. 2A, $\mathrm{B}$, red traces). However, the sharp rise has been observed at $\mathrm{pH} 8.5$ and was comparable to the white light oxidation rise (Fig. $2 \mathrm{C}$, red trace). The total yield of $\mathrm{Tyr}^{\bullet}$ under farred light illumination was $47 \%$ at $\mathrm{pH} 4.7,60 \%$ at $\mathrm{pH} 6.3$, and $105 \%$ at $\mathrm{pH} 8.5$. At $\mathrm{pH} 4.7$ and 6.3 Tyr oxidation never reached the steady-state level even after illumination for $325 \mathrm{~s}$ (Fig. 2A, B, red traces), whereas at $\mathrm{pH} 8.5$, the oxidation reached half of the level of tyrosine oxidation under white light illumination very fast within $50 \mathrm{~s}$ and was continued to slowly rise afterwards (Fig. 2C, red trace). Incubation of far-red illuminated samples for $5 \mathrm{~min}$ resulted in the additional rise of tyrosine amplitude at $\mathrm{pH} 4.7$ and 6.3 to $67 \%$ (Fig. 2A and B, red dot). In contrast, at pH 8.5 decrease of tyrosine amplitude to $91 \%$ was observed (Fig. 2C, red dot).

To conclude this part, continuous illumination of the reduced Mn-depleted PSII membranes with white light resulted in the formation of stable $\mathrm{Tyr}_{\mathrm{D}}{ }^{\bullet}$ radical at $\mathrm{pH} 4.7$ and 6.3 as could be judged from its post-illumination stability. The formation was much slower and less effective under far-red light illumination if compared with white light illumination. In contrast, at $\mathrm{pH} 8.5$ illumination with white light resulted in the formation of both $\operatorname{Tyr}_{\mathrm{Z}}{ }^{\bullet}$ radical and $\mathrm{Tyr}_{\mathrm{D}}{ }^{\bullet}$ radical, while illumination with far-red light resulted in albeit fast but only $\operatorname{Tyr}_{\mathrm{D}}{ }^{\bullet}$ formation. Thus, the only conditions radical after 5 min dark incubation is indicated as a black or red circle at the end of the each trace. The arrows indicate starting time point of illumination. EPR conditions: microwave frequency $9.75 \mathrm{GHz}$, microwave power $8 \mathrm{~mW}$, modulation amplitude $5 \mathrm{G}$, temperature $293 \mathrm{~K}$

which resulted in the observation of semi-stable $\operatorname{Tyr}_{\mathrm{Z}}{ }^{\bullet}$ were high $\mathrm{pH}$ and white light.

\section{Flash-induced tyrosine signal formation}

In order to further investigate the sequence of tyrosine radical formation in PS II, the monochromatic laser flashes at 532 and $732 \mathrm{~nm}$ were used. Figure $3 \mathrm{~A}-\mathrm{C}$ show the kinetic of $\operatorname{Tyr}_{\mathrm{Z}}{ }^{\bullet}$ and $\operatorname{Tyr}_{\mathrm{D}}{ }^{\bullet}$ formation and decay after five consecutive flashes separated by $5 \mathrm{~s}$ interval (indicated by arrows). Tyr ${ }^{\bullet}$ was formed after each flash is divided into the decaying and non-decaying tyrosine signal. According to the decay halftimes of $\operatorname{Tyr}_{\mathrm{Z}}{ }^{\bullet}$ and $\operatorname{Tyr}_{\mathrm{D}}{ }^{\bullet}$ in the Mn-depleted PSII preparations, the decaying part of tyrosine signal is attributed to $\operatorname{Tyr}_{\mathrm{Z}}{ }^{\bullet}$ and non-decaying part to $\operatorname{Tyr}_{\mathrm{D}}{ }^{\bullet}$ (Babcock and Sauer 1975a; Vass and Styring 1991). At pH 4.7, with green and far-red flashes, $\mathrm{Tyr}_{\mathrm{Z}}$ and $\mathrm{Tyr}_{\mathrm{D}}$ oxidation took place in 5-10\% of PS II centers (Fig. 3A). Similarly, very small induction of $\mathrm{Tyr}_{\mathrm{Z}}{ }^{\bullet}$ and $\mathrm{Tyr}_{\mathrm{D}}{ }^{\bullet}$ was observed at $\mathrm{pH} 6.3$ with far-red flashes (15-20\%, Fig. 3B, red trace). With green flashes at pH 6.3 however, both tyrosines were induced in the substantial number of PS II centers, resulting in $41 \%$ of non-decaying $\operatorname{Tyr}_{\mathrm{D}}{ }^{\bullet}$ (black trace). At $\mathrm{pH} 8.5$ significant amount of both tyrosines was formed at both wavelengths as could be judged from the decaying and non-decaying parts similarly to what was observed under continuous illumination. Again the final amplitude of $\operatorname{Tyr}_{\mathrm{D}}{ }^{\bullet}$ induced by green flashes (117\%) was higher than induced by far-red flashes (72\%, Fig. 3C).

Contribution of $\operatorname{Tyr}_{\mathrm{Z}}$ to the total oxidation process was studied in more detail in the same samples after $\operatorname{Tyr}_{\mathrm{D}}$ oxidation was completed (Fig. 3D-F). After accumulation, it is clear that $\mathrm{Tyr}_{\mathrm{Z}}{ }^{\bullet}$ signal was inducible at all three $\mathrm{pHs}$ by both 532 and $732 \mathrm{~nm}$ wavelengths. The amplitude of $\mathrm{Tyr}_{\mathrm{Z}}{ }^{\bullet}$ was twice higher after green flashes if compared to far-red 


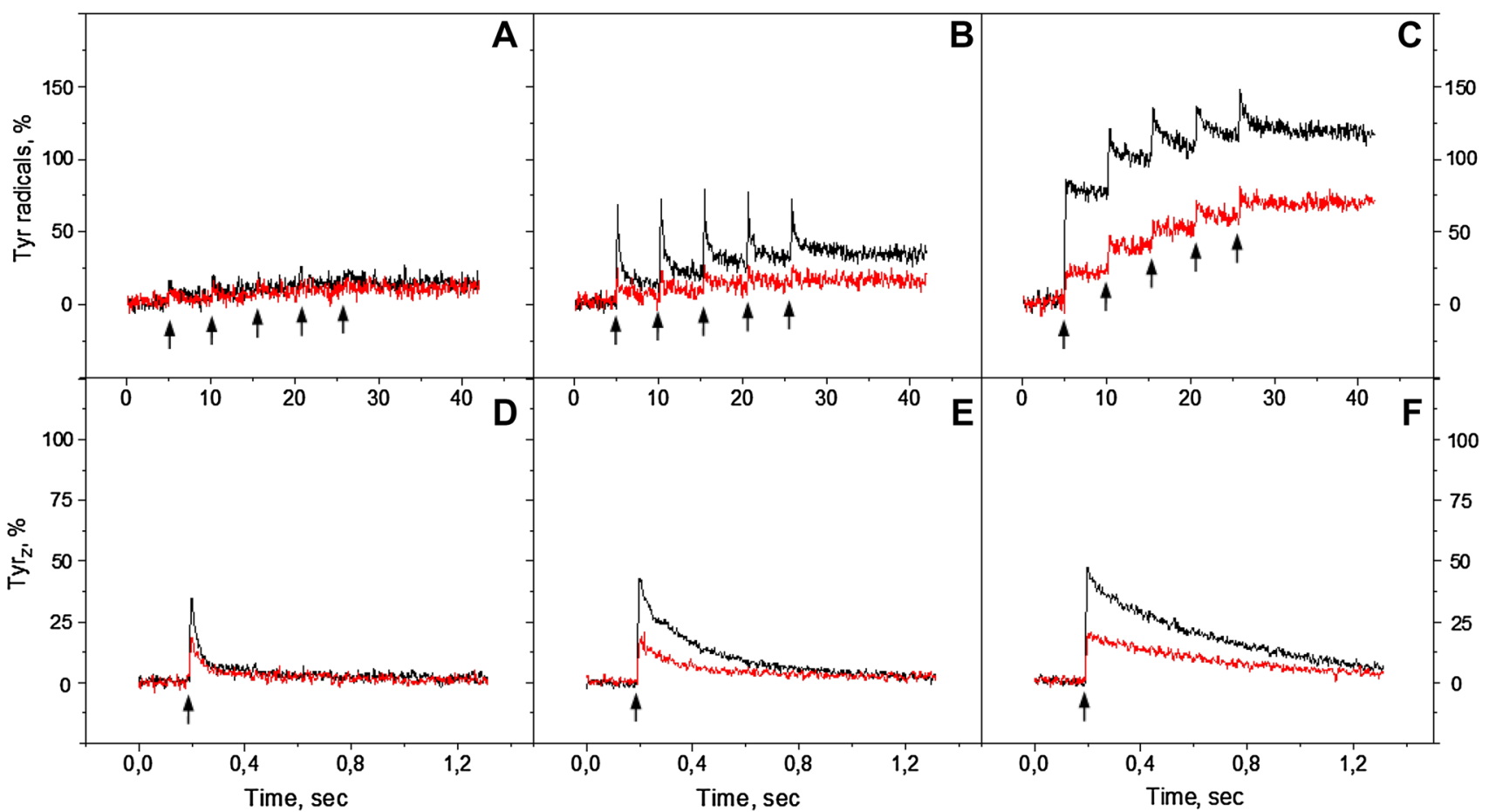

Fig. $3 \mathrm{Tyr}_{\mathrm{Z}}$ and $\mathrm{Tyr}_{\mathrm{D}}$ oxidation kinetics at $3465 \mathrm{G}$ in the reduced Mn-depleted PS II membranes, induced by a train of five $532 \mathrm{~nm}$ (black traces) or $732 \mathrm{~nm}$ laser flashes (red traces) at $\mathrm{pH} 4.7(\mathbf{A}), \mathrm{pH}$ $6.3(\mathbf{B})$ and $\mathrm{pH} 8.5(\mathbf{C})$. Each trace represents an average of four single measurements in independent samples. $\mathrm{Tyr}_{\mathrm{Z}}$ oxidation kinetics

flashes. Similarly to the continuous illumination experiments, $\mathrm{Tyr}_{\mathrm{Z}}$ oxidation was $\mathrm{pH}$ dependent and was small at $\mathrm{pH} 4.7$ and increased towards $\mathrm{pH}$ 8.5. This difference was pronounced with green flash induction (Fig. 3D-F, black traces). $\operatorname{Tyr}_{\mathrm{Z}}{ }^{\bullet}$ signal decay was also $\mathrm{pH}$ dependent and slowed down towards higher $\mathrm{pHs}$ with both wavelengths, from $21 \mathrm{~ms}$ at pH 4.7 to $596 \mathrm{~ms}$ at $\mathrm{pH} 8.5$ (Fig. 3D-F; Table 1).

\section{Influence of exogenous electron acceptor}

Better oxidation of tyrosines could be achieved by addition of ferricyanide which also prevents the loss of charge separation by recombination of $\mathrm{Q}_{\mathrm{A}}{ }^{-} \mathrm{Tyr}_{\mathrm{Z}}{ }^{\bullet}$ and $\mathrm{Q}_{\mathrm{B}}{ }^{-} \mathrm{Tyr}_{\mathrm{Z}}$ ' states (Bishop and Spikes 1955; Delrieu and Rosengard 1989). We have measured oxidation of tyrosine in the presence of ferricyanide in order to further understand the tyrosine oxidation in Mn-depleted PS II under continuous illumination with white and far-red light. Figure 4 (green traces) show the oxidation kinetics in the presence of ferricyanide at $\mathrm{pH} 4.7$, 6.3 and 8.5 respectively. At $\mathrm{pH} 4.7$ the amplitude of tyrosine oxidation was twice higher in the presence of ferricyanide if compared to a trace without any addition (Fig. 4, green traces). However, under far-red illumination, the kinetics induced by single $532 \mathrm{~nm}$ (black traces) or $732 \mathrm{~nm}$ laser flash (red traces) at: $\mathrm{pH} 4.7(\mathbf{D}), \mathrm{pH} 6.3(\mathbf{E})$ and $\mathrm{pH} 8.5(\mathbf{F})$. Each trace represents an average of 199 flashes. EPR conditions are the same as in Fig. 2

was slower, but more efficient, and still rising after $325 \mathrm{~s}$ of illumination (Fig. 4B, green trace).

The kinetics of tyrosine oxidation measured at $\mathrm{pH}$ 6.3 with the ferricyanide addition under white light was very similar to the kinetics obtained without any additions ( $100 \%$ oxidation), except for the absence of the small decay after the maximum amplitude was reached (Fig. 4C, green and black traces). This is reasonable since the presence of the acceptor is preventing decay to the steady-state equilibrium between tyrosine oxidation and recombination reactions. Under far-red light however, the oxidation kinetics were much slower and rose to the higher level in the presence of ferricyanide than without any additions and reached the same amplitude (100\%) as under white light illumination (Fig. 4D, green trace). At higher $\mathrm{pH}$, under white light illumination, the oxidation kinetics and amplitude were again very similar in the presence or absence of ferricyanide reaching ca $200 \%$ indicating full oxidation of both $\mathrm{Tyr}_{\mathrm{Z}}$ and $\mathrm{Tyr}_{\mathrm{D}}$ (Fig. 4E, green and black traces). Interestingly, under far-red light at $\mathrm{pH} 8.5$, the amplitude was higher than without acceptor almost reaching $142 \%$ (Fig. 4F, green trace) if compared to the black trace without additions (100\%). This indicates that in addition to the full induction of $\operatorname{Tyr}_{\mathrm{D}} \cdot, 50 \%$ of $\operatorname{Tyr}_{\mathrm{Z}}{ }^{\bullet}$ was induced by 


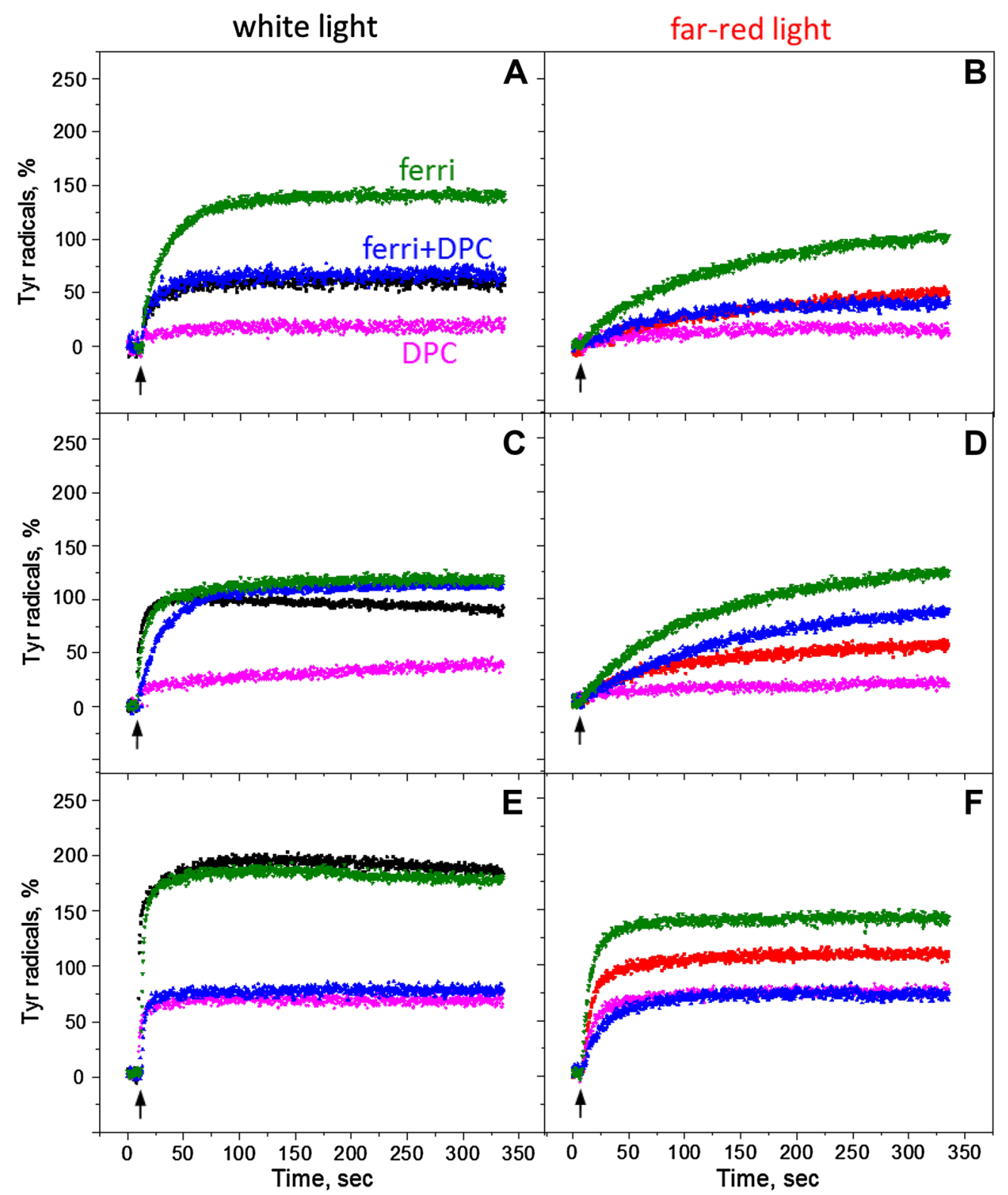

Fig. 4 Kinetics of tyrosine oxidation recorded under white light (A, $\mathbf{C}, \mathbf{E}$, black traces) or far-red light illumination $(\mathbf{B}, \mathbf{D}, \mathbf{F}$, red traces $)$ at $\mathrm{pH} 4.7(\mathbf{A}, \mathbf{B}), \mathrm{pH} 6.3(\mathbf{C}, \mathbf{D})$ and $\mathrm{pH} 8.5(\mathbf{E}, \mathbf{F})$. Pink traces-in

far-red light at pH 8.5 in the Mn-depleted PS II centers. The rise of the signal was also fast and comparable to the white light induction at these conditions.

\section{Influence of exogenous electron donor}

To distinguish between direct (by $\mathrm{P}_{680}{ }^{+}$) or indirect (via equilibrium with $\operatorname{Tyr}_{Z}{ }^{\bullet}$, see Scheme 2) oxidation of $\operatorname{Tyr}_{D}$, DPC as an exogenous electron donor to $\mathrm{Tyr}_{\mathrm{Z}}{ }^{\bullet}$ was added to the samples before illumination. It is known that addition of DPC accelerates the $\mathrm{Tyr}_{\mathrm{Z}}{ }^{\bullet}$ lifetime and this makes the presence of $1 \mathrm{mM}$ DPC; green traces - in the presence of $2 \mathrm{mM}$ ferricyanide and blue trace-in the presence of $1 \mathrm{mM} \mathrm{DPC}$ and $2 \mathrm{mM}$ ferricyanide. EPR conditions are the same as in Fig. 2

it less available for $\operatorname{Tyr}_{\mathrm{D}}$ oxidation (Babcock and Sauer 1975b; Yerkes and Babcock 1980; Roffey et al. 1994). Figure 4A-D (pink traces) show oxidation kinetics under continuous white and far-red light illumination in the presence of DPC at pH 4.7 and 6.3, respectively. It is clear that addition of DPC significantly inhibited tyrosine oxidation in the majority of PS II centers under both illuminating conditions. At pH 6.3 oxidation was slightly better than at $\mathrm{pH} 4.7$; however, at both $\mathrm{pHs}$ tyrosine oxidation did not reach the complete equilibrium and the kinetics were still rising after $325 \mathrm{~s}$ of both white and far-red light 


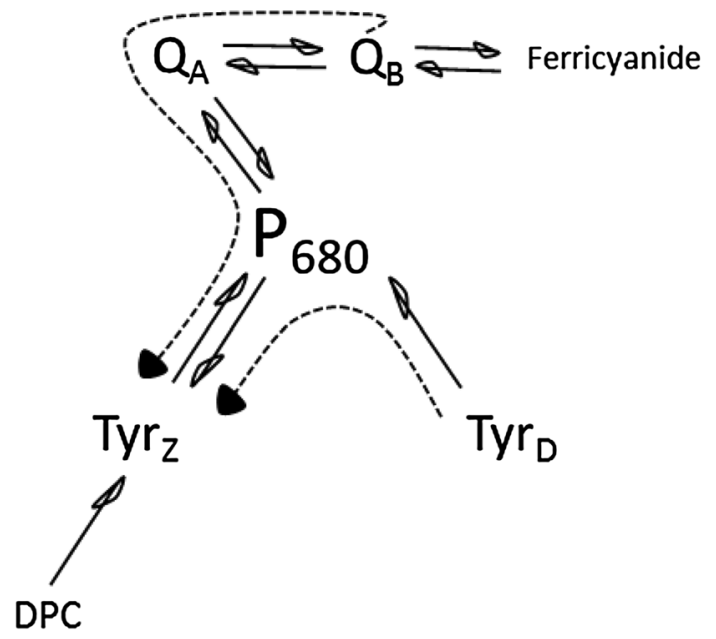

Scheme 2 Electron transfer events and redox equilibria leading to $\mathrm{Tyr}_{\mathrm{D}}$ and $\mathrm{Tyr}_{\mathrm{Z}}$ oxidation in the Mn-depleted PS II centers

illumination (Fig. 4A-D, pink traces). Interestingly, at $\mathrm{pH}$ 8.5 the tyrosine induction was better and both white and far-red light illumination have the same effect on oxidation which reached $70 \%$ of the PS II centers (Fig. 4E, F, pink traces).

We also performed these measurements in the presence of both exogenous donor and acceptor, DPC and ferricyanide, to see how the steady-state equilibrium between tyrosine oxidation and recombination reaction will be affected (Fig. 4, blue traces). The effect was very $\mathrm{pH}$ dependent. At pH 4.7 the presence of both DPC and ferricyanide resulted in higher tyrosine amplitude than in the presence of only DPC under both light conditions (Fig. 4A, $\mathrm{B}$, blue traces). It restored amplitude to the level which was achieved in the measurements without any additions (compare to black and red traces). At pH 6.3 the effect was bigger and final amplitude of $\mathrm{Tyr}^{\bullet}$ was significantly higher than in the presence of only DPC and 25-35\% higher than in a sample without any additions (Fig. 4, compare black, pink, and blue traces (C) and red, pink, and blue traces (D). The oxidation kinetics under white light was however slowed down (Fig. 4C, blue trace). At pH 8.5 addition of ferricyanide had no effect and the final oxidation level was very similar to the level obtained only in the presence of DPC (Fig. 4E, F, pink and blue traces).

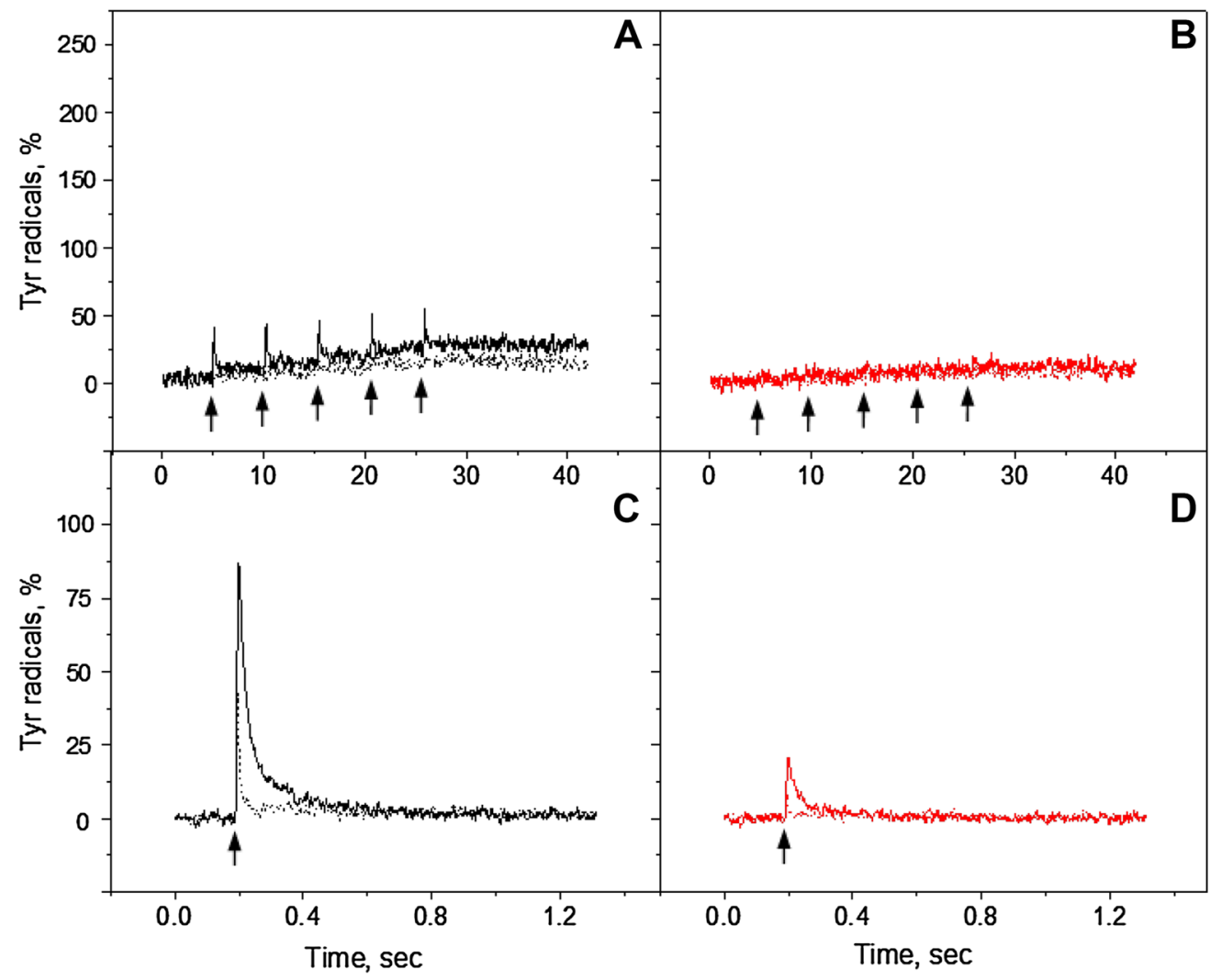

Fig. $5 \mathrm{Tyr}_{\mathrm{Z}}$ and $\mathrm{Tyr}_{\mathrm{D}}$ oxidation kinetics in the reduced Mn-depleted PS II membranes, induced by a train of five $532 \mathrm{~nm}$ (A, black traces) or $732 \mathrm{~nm}$ laser flashes (B, red traces) at $\mathrm{pH} 4.7$ in the presence of $2 \mathrm{mM}$ ferricyanide (solid line) or in the presence of $2 \mathrm{mM}$ ferricyanide and $2 \mathrm{mM}$ DPC (dotted line). $\mathrm{Tyr}_{\mathrm{Z}}$ oxidation kinetics induced by single $532 \mathrm{~nm}$ (C, black traces) or $732 \mathrm{~nm}$ laser flash (D, red traces) at $\mathrm{pH} 4.7$ in the presence of $2 \mathrm{mM}$ ferricyanide (solid line) or in the presence of $2 \mathrm{mM}$ ferricyanide and $2 \mathrm{mM}$ DPC (dotted line). EPR conditions are the same as in Fig. 3 


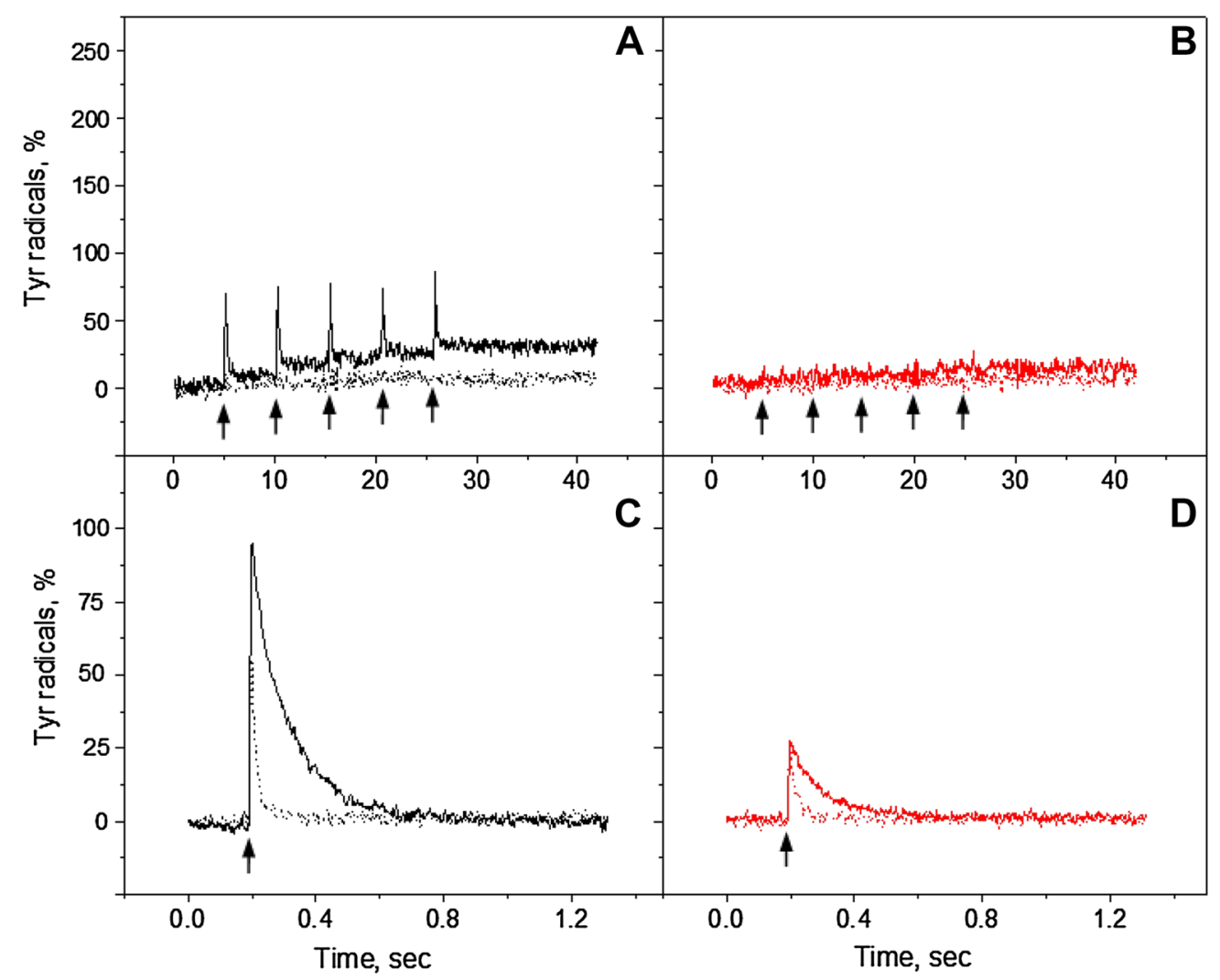

Fig. $6 \mathrm{Tyr}_{\mathrm{Z}}$ and $\mathrm{Tyr}_{\mathrm{D}}$ oxidation kinetics in the reduced Mn-depleted PS II membranes, induced by a train of five $532 \mathrm{~nm}$ (A, black traces) or $732 \mathrm{~nm}$ laser flashes (B, red traces) at $\mathrm{pH} 6.3$ in the presence of $2 \mathrm{mM}$ ferricyanide (solid line) or in the presence of $2 \mathrm{mM}$ ferricyanide and $2 \mathrm{mM}$ DPC (dotted line). $\mathrm{Tyr}_{\mathrm{Z}}$ oxidation kinetics induced by

It should be noted that only $\operatorname{Tyr}_{\mathrm{D}}{ }^{\bullet}$ was formed in the presence of DPC or DPC and ferricyanide under both white and far-red light as can be estimated from the residual signal after the light was switched off (not shown). We were not able to observe any fast decaying $\operatorname{Tyr}_{\mathrm{Z}}{ }^{\bullet}$ and the signal was never higher than $100 \%$ at all $\mathrm{pH}$ values measured. Our conclusion from these measurements is that DPC is an effective donor to $\mathrm{Tyr}_{\mathrm{Z}}{ }^{\bullet}$ at all three $\mathrm{pH}$ values and the addition of ferricyanide only eliminates the recombination reaction from the acceptor side of PS II which takes place at low $\mathrm{pH}$ values (Ahmadova et al. 2017).

\section{Flash-induced tyrosine signal formation in the presence of donor and acceptor}

Figures 5, 6, and 7 show the kinetics of $\mathrm{Tyr}_{\mathrm{Z}}$ and $\mathrm{Tyr}_{\mathrm{D}}$ formation and decay after five consecutive laser flashes separated by $5 \mathrm{~s}$ each (indicated by arrows) in the presence of electron donor and acceptor. In the presence of only ferricyanide we observed $\mathrm{Tyr}_{\mathrm{Z}}$ oxidation at $\mathrm{pH} 4.7$ and 6.3 from the first given green flash (Figs. 5A, 6A, black solid traces). At $\mathrm{pH} 8.5$ oxidation was very efficient and resulted single $532 \mathrm{~nm}$ (C, black traces) or $732 \mathrm{~nm}$ laser flash (D, red traces) at $\mathrm{pH} 6.3$ in the presence of $2 \mathrm{mM}$ ferricyanide (solid line) or in the presence of $2 \mathrm{mM}$ ferricyanide and $2 \mathrm{mM}$ DPC (dotted line). EPR conditions are the same as in Fig. 3

in complete oxidation of $\mathrm{Tyr}_{\mathrm{Z}}$ with consequent decay and of $\mathrm{Tyr}_{\mathrm{D}}$ (Fig. 7A, black solid trace). Interestingly, no fast decay was observed after the first flash, similar to measurements without any additions (Fig. 3C, black trace).

Interestingly, we did not detect $\mathrm{Tyr}_{\mathrm{Z}}$ oxidation with single far-red flashes in the presence of ferricyanide and final $\mathrm{Tyr}_{\mathrm{D}}$ oxidation was less than $12 \%$ at $\mathrm{pH} 4.7$ or at $\mathrm{pH} 6.3$ (Figs. 5B, $6 \mathrm{~B}$, red solid traces). At $\mathrm{pH} 8.5$ with far-red flashes, we observed almost full oxidation of $\mathrm{Tyr}_{\mathrm{D}}$ after five flashes ( $80 \%$, Fig. 7B, red solid trace). Unlike in oxidation with green flashes, the fast decay kinetics $\left(\mathrm{Tyr}_{\mathrm{Z}}{ }^{\circ}\right)$ was observed on the third flash and onward but seemingly the first two flashes induced only $\mathrm{Tyr}_{\mathrm{D}}$ oxidation in the majority PS II centers at high $\mathrm{pH}(48 \%$, Fig. 7B, red solid trace).

Accumulated $\operatorname{Tyr}_{\mathrm{Z}}{ }^{\bullet}$ signal induced by green or far-red flashes in the presence of ferricyanide is shown in Figs. 5, 6 , and $7 \mathrm{C}$ and $\mathrm{D}$, solid traces. With $532 \mathrm{~nm}$ induction, the amplitude of $\operatorname{Tyr}_{\mathrm{Z}}{ }^{\bullet}$ slightly increased towards high $\mathrm{pH}$ and corresponded to $85 \%$ at $\mathrm{pH} 4.7,95 \%$ at $\mathrm{pH} 6.3$, and $109 \%$ at pH 8.5. With $732 \mathrm{~nm}$ induction, we observed only $20 \%$ at $\mathrm{pH} 4.7,27 \%$ at $\mathrm{pH} 6.3$, and $37 \%$ at $\mathrm{pH} 8.5$. The decay halftimes were also $\mathrm{pH}$ dependant and corresponded to $22 \mathrm{~ms}$ 


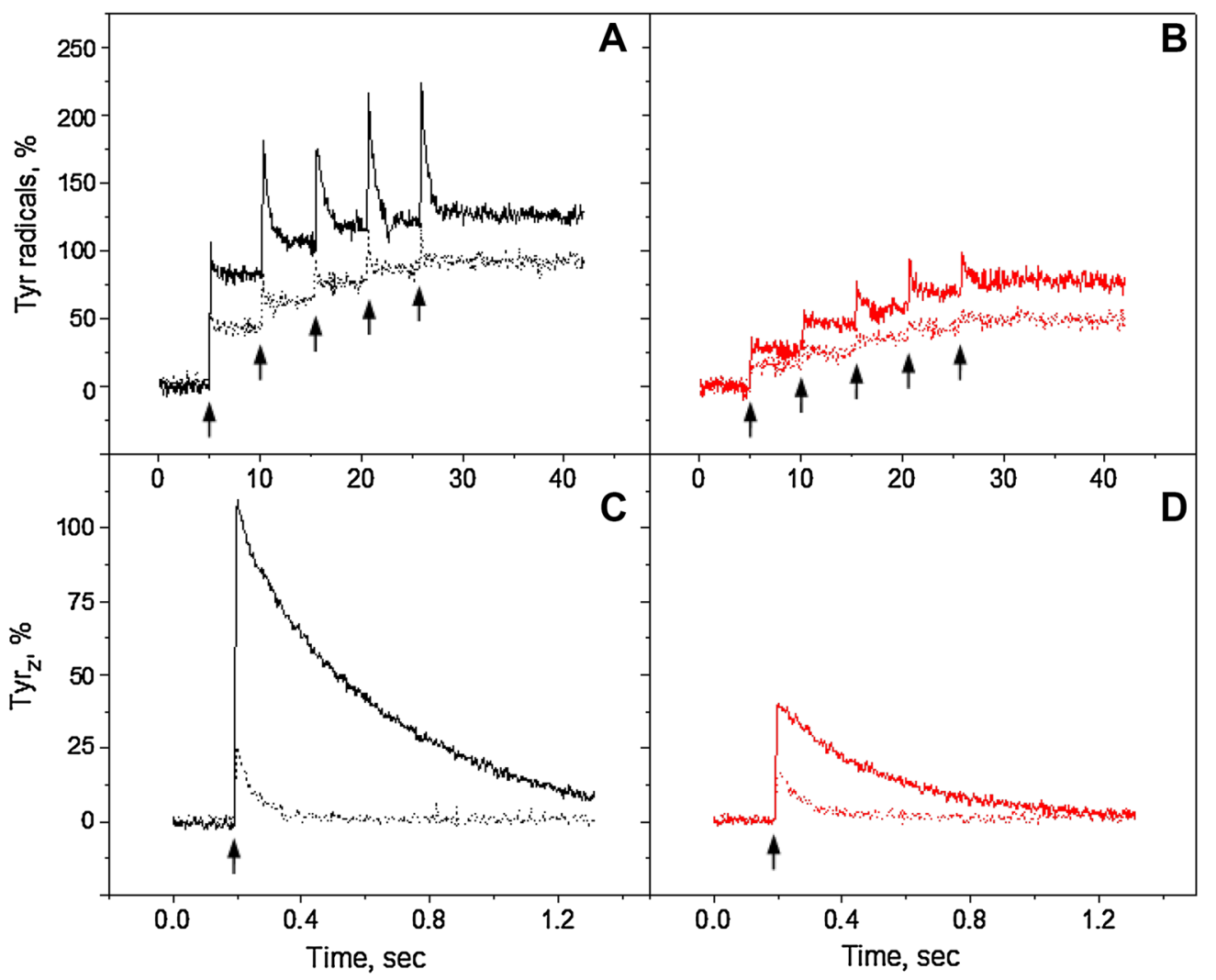

Fig. $7 \mathrm{Tyr}_{\mathrm{Z}}$ and $\mathrm{Tyr}_{\mathrm{D}}$ oxidation kinetics in the reduced Mn-depleted PS II membranes, induced by a train of five $532 \mathrm{~nm}$ (A, black traces) or $732 \mathrm{~nm}$ laser flashes (B, red traces) at $\mathrm{pH} 8.5$ in the presence of $2 \mathrm{mM}$ ferricyanide (solid line) or in the presence of $2 \mathrm{mM}$ ferricyanide and $2 \mathrm{mM}$ DPC (dotted line). $\mathrm{Tyr}_{\mathrm{Z}}$ oxidation kinetics induced by

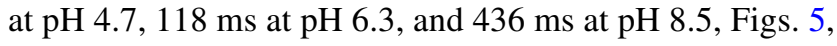
6 , and $7 \mathrm{C}$ and $\mathrm{D}$, solid traces, Table 1 . The decay half-time was independent of the induction wavelength.

We also investigated the kinetics of flash-induced tyrosine signal formation in the presence of both DPC and ferricyanide (Figs. 5, 6, 7A and B, dotted traces). The addition of DPC almost completely inhibited the tyrosine formation at $\mathrm{pH} 4.7$ and 6.3. We did not observe any $\mathrm{Tyr}_{\mathrm{Z}}{ }^{\bullet}$ formation in the presence of DPC and the final $\operatorname{Tyr}_{\mathrm{D}}{ }^{\bullet}$ formation was less than $5 \%$ at these two $\mathrm{pH}$ values (Figs. 5, 6A and B, dotted traces). At $\mathrm{pH} 8.5$, the $\mathrm{Tyr}_{\mathrm{Z}}{ }^{\bullet}$ signal was still unresolvable in the presence of DPC but $\operatorname{Tyr}_{\mathrm{D}}$ oxidation occurred in the majority of the PS II centers with $532 \mathrm{~nm}$ flashes (>75\%, Fig. 7A, black-dotted trace) and in less centers with $732 \mathrm{~nm}$ flashes (45\%, Fig. 7B, red-dotted trace). Figures 5, 6, and 7C and D show that in the presence of DPC the $\mathrm{Tyr}_{\mathrm{Z}}{ }^{\bullet}$ induction is strongly inhibited and very short lived (ca $20 \mathrm{~ms}$ or less, Table 1) at low $\mathrm{pH}$ values, while at high $\mathrm{pH}$ the half-time was less affected and significant loss of $\mathrm{Tyr}_{\mathrm{Z}}{ }^{\bullet}$ amplitude could be attributed to competitive reduction of $\mathrm{P}_{680}{ }^{+}$by Tyr ${ }_{\mathrm{D}}$ (Scheme 2) (Fig. 7C, D, dotted traces). single $532 \mathrm{~nm}$ (C) black traces) or $732 \mathrm{~nm}$ laser flash (D, red traces) at $\mathrm{pH} 8.5$ in the presence of $2 \mathrm{mM}$ ferricyanide (solid line) or in the presence of $2 \mathrm{mM}$ ferricyanide and $2 \mathrm{mM}$ DPC (dotted line). EPR conditions are the same as in Fig. 3

\section{Discussion}

The special Chl molecules, $\mathrm{P}_{680}$, serve as a primary electron donor in PS II. $\mathrm{P}_{680}$ is a tetrameric pigment entity which comprises four $\mathrm{Chl}$ molecules. The central $\mathrm{Chl}$ pair, $\mathrm{P}_{\mathrm{D} 1}$ and $\mathrm{P}_{\mathrm{D} 2}$ are weakly excitonically coupled and situated at $30^{\circ}$ angle to the horizontal plane. The other two Chls, $\mathrm{Chl}_{\mathrm{D} 1}$ and $\mathrm{Chl}_{\mathrm{D} 2}$ are occupying symmetrical positions at $10 \AA$ center-to-center distance each from $\mathrm{P}_{\mathrm{D} 1}$ and $\mathrm{P}_{\mathrm{D} 2}$, respectively (Scheme 1) (Umena et al. 2011; Suga et al. 2015; Wei et al. 2016). The localization of excitation energy in $P_{680}$ and the first $\mathrm{Chl}^{+}$electron donor formed after the "standard" charge separation conditions (visible-light excitation) have been extensively studied by different spectroscopic methods (Zech et al. 1997; Diner et al. 2001; Groot et al. 2005; Holzwarth et al. 2006; Romero et al. 2010, 2012). The primary hole is consensually placed on the $\mathrm{P}_{\mathrm{D} 1} \mathrm{Chl}\left(\mathrm{P}_{\mathrm{D} 1}{ }^{+}\right)$(Scheme 1) (Hillmann et al. 1995; Diner et al. 2001; Schlodder et al. 2008b; Cardona et al. 2012) although some groups reported that weak spectral differentiation among all four Chls might lead to a distribution of the excitation energy at ambient temperature (Romero et al. 2010, 2012). There are also reports 
that the reduction of $\mathrm{PheO}_{\mathrm{D} 1}$, which is the primary acceptor in PS II (Scheme 1) occurs prior to the oxidation of $\mathrm{P}_{\mathrm{D} 1} / \mathrm{P}_{\mathrm{D} 2}$ (Groot et al. 2005; Holzwarth et al. 2006).

The far-red photochemistry at low temperature has been suggested to induce different primary charge pair, $\mathrm{Chl}_{\mathrm{D} 1}{ }^{+}$ $\mathrm{Pheo}^{-}$(Mokvist et al. 2014). This was based on the different donation efficiency to $\mathrm{P} 680^{+}$from $\mathrm{Tyr}_{\mathrm{Z}}$ and $\mathrm{Cyt} \mathrm{b}_{559} / \mathrm{Chl}_{\mathrm{Z}}$ pathways under green and far-red illumination at $5 \mathrm{~K}$, in the so-called product analysis of the charge-separated state (Mokvist et al. 2014). It seems that nature of the primary electron hole in $\mathrm{P}_{680}{ }^{+}$varies depending on the temperature and excitation wavelength (Raszewski et al. 2008). In this paper, we investigate if the similar effect of excitation wavelength (visible vs. far-red light) on the primary donor occurs at physiological conditions. $\mathrm{Tyr}_{\mathrm{Z}}$ and $\mathrm{Tyr}_{\mathrm{D}}$, which are symmetrically positioned at about $9.2 \AA$ distance from the central $P_{D 1}$ and $P_{D 2}$ Chls, respectively, (Scheme 1) were used as competing electron donors to elucidate the nature of the primary charge-separated state at room temperature.

The task is complicated by the fact that there are two electron transfer pathways for $\mathrm{Tyr}_{\mathrm{D}}$ to be oxidized in the Mndepleted PS II. The first one is occurring via $\mathrm{Tyr}_{\mathrm{Z}} \bullet$ which is formed rapidly after oxidation by $\mathrm{P}_{680}{ }^{+}$. ${ }^{-} \mathrm{Tyr}_{\mathrm{D}}$, with its lower redox potential, is then slowly oxidized in the following reaction (Boussac and Etienne 1982c, 1984; Faller et al. 2001):

$T y r_{D} T y r_{Z} \stackrel{\text { light }}{\longrightarrow} T y r_{D} T y r_{Z}^{\circ} \rightarrow T y r_{D}^{\cdot} T y r_{Z}$

This oxidation pathway occurs at low and middle $\mathrm{pH}$ values. However, at high pH (above $\mathrm{pK}_{\mathrm{a}}$ of $\operatorname{Tyr}_{\mathrm{D}}$ (Vass 1991; Faller et al. 2001; Ahmadova et al. 2017)), direct $\mathrm{Tyr}_{\mathrm{D}}$ oxidation by $\mathrm{P}_{680}{ }^{+}$was reported in the Mn-depleted preparation in at least half of the PS II centers (Faller et al. 2001). As a result, partial localization of the electron hole on $\mathrm{P}_{\mathrm{D} 2} \mathrm{Chl}$ was suggested (Faller et al. 2001).

Our data show that under continuous illumination we mostly observed oxidation of $\operatorname{Tyr}_{\mathrm{D}}$ (except white light illumination at high $\mathrm{pH}$ where both $\operatorname{Tyr}_{\mathrm{Z}}{ }^{\bullet}$ and $\operatorname{Tyr}_{\mathrm{D}}{ }^{\bullet}$ were formed (Fig. 2)). The $\mathrm{pH}$ dependence of $\operatorname{Tyr}_{\mathrm{D}}{ }^{\bullet}$ induction was similar to what was reported on green flash-induced $\operatorname{Tyr}_{\mathrm{D}}{ }^{\bullet}$ formation in intact PS II (Vass and Styring 1991; Sjöholm et al. 2016; Ahmadova et al. 2017). In our Tris-washed PSII membranes, under continuous white light illumination $\operatorname{Tyr}_{\mathrm{D}}$ oxidation takes place in 65 and $100 \%$ at pH 4.7 and 6.3, respectively (Fig. 2A, B, black traces). With far-red light illumination (732 nm LED light), oxidation at these $\mathrm{pH}$ values was much slower and less effective (Fig. 2A, B, red traces). The diminished formation of $\mathrm{Tyr}_{\mathrm{D}}$ under far-red light could be due to either less effective charge separation or due to the different nature of the primary donor which makes the far-red photochemistry less effective.
The first hypothesis seems unlikely because under $732 \mathrm{~nm}$ light most of the PS II centers undergo charge separation. As it was shown by (Thapper et al. 2009) illumination with $730 \mathrm{~nm}$ light resulted in $\mathrm{P}_{680}{ }^{+} \mathrm{Pheo}^{-}$primary charge pair formation in the vast majority of the PS II centers. This is by far in more centers than the decreased tyrosine radical formation under similar $732 \mathrm{~nm}$ illumination (Fig. 2A, B). Thus, the possibility of the second hypothesis cannot be ruled out. At pH 8.5 continuous white light illumination induces both tyrosines. Interestingly, illumination with $732 \mathrm{~nm}$ light resulted in only $\operatorname{Tyr}_{\mathrm{D}}{ }^{\bullet}$ formation (Fig. 2C, red trace). Full induction of $\operatorname{Tyr}_{\mathrm{D}}{ }^{\bullet}(100 \%)$ also indicates that far-red light excites $100 \%$ of the PS II centers, as mentioned above. The difference between tyrosine formation at $\mathrm{pH} 8.5$ under visible and far-red illumination could originate either from different tyrosine oxidation pathways $\left(\mathrm{Tyr}_{\mathrm{D}} \mathrm{vs} \mathrm{Tyr}_{\mathrm{Z}}\right)$ or different localizations of the primary donor. Here our data with the addition of exogenous donor and acceptor to regulate the "redox pressure" in and out from $\mathrm{Tyr}_{\mathrm{Z}}$ ' (Scheme 2) will help to answer these questions.

The addition of ferricyanide increased oxidation amplitude of $\mathrm{Tyr}_{\mathrm{D}}$ at low $\mathrm{pH}$ by efficiently preventing recombination from the acceptor side of PS II (Fig. 4, green traces). At $\mathrm{pH} 6.3$ and 8.5, the effect of ferricyanide addition was only observable under the far-red illumination (Fig. 4D, F). Since we also observed that the addition of ferricyanide also increased the amplitude of $\operatorname{Tyr}_{\mathrm{Z}}{ }^{\bullet}$ induction (Table 1), it is clear that final oxidation of $\operatorname{Tyr}_{\mathrm{D}}$, at $\mathrm{pH} 4.7$ and 6.3, takes place via $\operatorname{Tyr}_{\mathrm{Z}}{ }^{\bullet}$ as described in reaction (1). More importantly, this indicates that recombination reaction was more efficiently prevented by the ferricyanide addition under farred light illumination. This implies different recombination partners formed under the far-red light on the donor side of PS II. Since $\operatorname{Tyr}_{\mathrm{Z}}{ }^{\bullet}$ is the same at both illumination conditions, the only difference could be assumed at the $\mathrm{P}_{680}{ }^{+}$ entity.

The most important and informative results were obtained when measurements were done in the presence of DPC. DPC is known to be an efficient electron donor to $\operatorname{Tyr}_{\mathrm{Z}}{ }^{\bullet}$ in the Mn-depleted PS II preparations (Babcock and Sauer 1975b; Yerkes and Babcock 1980; Roffey et al. 1994). In our case, both $\operatorname{Tyr}_{\mathrm{D}}$ and DPC are competing for the $\mathrm{Tyr}_{\mathrm{Z}}{ }^{\text {- }}$ reduction and in the presence of DPC the decay half-time of $\mathrm{Tyr}_{\mathrm{Z}}{ }^{\bullet}$ is significantly decreased (Table 1); thus, effectively blocking indirect $\operatorname{Tyr}_{\mathrm{D}}$ oxidation (Scheme 2). The addition of DPC severely inhibited $\mathrm{Tyr}_{\mathrm{D}}{ }^{\bullet}$ formation at $\mathrm{pH} 4.7$ and 6.3 under both white and far-red illuminations (Fig. 4A-D, pink traces). DPC inhibition of the $\operatorname{Tyr}_{\mathrm{D}}{ }^{\bullet}$ formation was more effective under far-red light illumination (only 18 and $19 \%$ formation at $\mathrm{pH} 4.7$ and 6.3, respectively). Interestingly, even under white light illumination at $\mathrm{pH} 8.5$ only $\operatorname{Tyr}_{\mathrm{D}}$ oxidation was observed in the presence of DPC and no extra intensity could be attributed to the $\mathrm{Tyr}_{\mathrm{Z}}$ oxidation 
(Fig. 4E, F, pink traces). This is another indication for the direct oxidation of $\mathrm{Tyr}_{\mathrm{D}}$ by $\mathrm{P}_{680}{ }^{+}$at high $\mathrm{pH}$ (Scheme 2) (Faller et al. 2001).

In the presence of both DPC and ferricyanide, the oxidation kinetics was found to be similar to what was found in the absence of any additions (Fig. 4A-D, blue traces). In this case, availability of the electron donor (DPC) and acceptor (ferricyanide) to and from $\mathrm{Tyr}_{\mathrm{Z}}$ allowed the same final steady-state oxidation level, thus, effectively restoring the original "redox pressure" on $\mathrm{Tyr}_{\mathrm{Z}}$ '.

Flash-induced $\operatorname{Tyr}_{\mathrm{Z}}{ }^{\bullet}$ oxidation was observed at all $\mathrm{pHs}$ and under both 532 and $732 \mathrm{~nm}$ laser flash in our Triswashed PS II membranes. It was both $\mathrm{pH}$ dependent (as was reported before (Boska et al. 1983)) and wavelength dependent (Table 1; Figs. 3E, D, and 5, 6, 7C and D). The decay half-time of $\mathrm{Tyr}_{\mathrm{Z}}{ }^{\bullet}$ was $\mathrm{pH}$ dependent (Babcock and Sauer 1975a; Shigemori et al. 1997) but wavelength independent (Table 1). This indicates that after the $\operatorname{Tyr}_{\mathrm{Z}}{ }^{\bullet}$ formation (if any), its consequent reduction either from $\operatorname{Tyr}_{\mathrm{D}}{ }^{\bullet}$ or DPC (when present) or by recombination from the acceptor side (Scheme 2) was independent on the way of how the primary charge separation occurred. At $\mathrm{pH} 4.7$ and 6.3 the presence of DPC decreased the amplitude of $\mathrm{Tyr}_{\mathrm{Z}}{ }^{\bullet}$, especially under $732 \mathrm{~nm}$ flash (to final $3 \%$ and $25 \%$, respectively if compared to $532 \mathrm{~nm}$ flash (Figs. 5, 6C and D; Table 1)). This resulted in significantly less $\operatorname{Tyr}_{\mathrm{D}}{ }^{\bullet}$ formation, especially after far-red flashes (Figs. 5, 6A and B). In contrast at high $\mathrm{pH} 8.5$, even if the effect of DPC addition on $\mathrm{Tyr}_{\mathrm{Z}}{ }^{\bullet}$ kinetics was similarly dramatic, a significant amount of $\operatorname{Tyr}_{\mathrm{D}}{ }^{\bullet}$ was formed. The absence of the fast decay on the first flash in Fig. 7A, B points out to the direct oxidation of $\operatorname{Tyr}_{\mathrm{D}}{ }^{\bullet}$ by $\mathrm{P}_{680}{ }^{+}$under both green and far-red (although much less efficiently) flashes.

Thus, our data indicate that different photochemistry is involved in oxidation of two tyrosines in the Mn-depleted PS II membranes. The far-red light-induced photochemistry is taking place in the majority of the PS II centers. At normal $\mathrm{pH}$ values, it results in the decrease of $\mathrm{Tyr}_{\mathrm{Z}}{ }^{\bullet}$ formation and correspondingly higher recombination rate under the far-red light illumination. Recombination reaction takes place between the acceptor side of PS II $\left(\mathrm{Q}_{\mathrm{A}}{ }^{-}\right.$or $\left.\mathrm{Q}_{\mathrm{B}}{ }^{-}\right)$and $\mathrm{P}_{680}{ }^{+}$which prevents $\mathrm{Tyr}_{\mathrm{Z}}{ }^{\bullet}$ formation. The reason for this could be a different primary charge separation event and correspondingly the localization of the electron hole in $\mathrm{P}_{680}{ }^{+}$ (Scheme 1).

The central Chl pair, $\mathrm{P}_{\mathrm{D} 1}$ and $\mathrm{P}_{\mathrm{D} 2}$ is excitonically weakly coupled. The greater physical separation, the slight differences in tetrapyrrole ring orientation, and the smaller dipole strength of the $\mathrm{Q}_{\mathrm{y}}$ transition cause weaker electronic interaction between special Chl pair (Diner and Rappaport 2002; Raszewski et al. 2005; Schlodder et al. 2008a). This is why the Chl pair, $\mathrm{P}_{\mathrm{D} 1}$ and $\mathrm{P}_{\mathrm{D} 2}$ do not represent the lowest energy sink for the excitation energy (Diner and Rappaport 2002;
Raszewski et al. 2005; Schlodder et al. 2008a). Whereas the monomeric $\mathrm{Chl}_{\mathrm{D} 1}$ has the lowest site energy because of the absence of such coupling (Schlodder et al. 2008a). The far-red light bears low excitation energy if compared to white light. Therefore, far-red light-induced excitation migration among four Chls in $\mathrm{P}_{680}$ would be an energetically less favorable process. It is more likely that under the far-red light the excitation localized on $\mathrm{Chl}_{\mathrm{D} 1}$, closer to the primary electron acceptor, Pheo (Scheme 1) was shown to take place at very low temperatures (Mokvist et al. 2014).

Localization of the electron hole on $\mathrm{Chl}_{\mathrm{D} 1}$ is not an ideal situation since recombination from the acceptor side $\mathrm{Chl}_{\mathrm{D} 1}{ }^{+}$ $\mathrm{Q}_{\mathrm{A}}{ }^{-}$is faster and efficiently quenches productive charge separation. On the other hand, $\mathrm{Tyr}_{\mathrm{Z}}$ is still in the close distance to both $\mathrm{Chl}_{\mathrm{D} 1}$ and $\mathrm{P}_{\mathrm{D} 1}$ to have an efficient donation in the centers where $\mathrm{Chl}_{\mathrm{D} 1}{ }^{+}$is still available. Moreover, at physiological temperatures, as soon as $\mathrm{Chl}_{\mathrm{D} 1}$ loses an electron, the hole can migrate to the neighboring $\mathrm{P}_{\mathrm{D} 1}$ and $\mathrm{P}_{\mathrm{D} 2}$. After the hole jumps on $\mathrm{P}_{\mathrm{D} 1}$, the localization of the hole on $\mathrm{P}_{\mathrm{D} 1}$ or $\mathrm{P}_{\mathrm{D} 2}$ becomes a very random process. This why at high $\mathrm{pH}$ direct oxidation of $\mathrm{Tyr}_{\mathrm{D}}$ by $\mathrm{P}_{680}{ }^{+}$( via $\mathrm{P}_{\mathrm{D} 2}{ }^{+}$as was suggested by Faller et al. 2001) is possible at least in part of the PS II centers under the far-red light illumination.

Thus, our results indicate that in the Mn-depleted PS II at room temperature the primary charge separation pathway under the far-red excitation occurs via $\mathrm{Chl}_{\mathrm{D} 1}{ }^{+} \mathrm{Phe}_{\mathrm{D} 1}{ }^{-}$primary pair, similar to what was reported for the active PS II at ultra-low temperature (Mokvist et al. 2014). The question if the same reaction occurs in the active PS II under physiological conditions requires further investigations.

Acknowledgements The Swedish Research Council is gratefully acknowledged for the financial support. NA further acknowledges the State Oil Fund of Azerbaijan for a PhD research stipend.

Open Access This article is distributed under the terms of the Creative Commons Attribution 4.0 International License (http://creativecommons.org/licenses/by/4.0/), which permits unrestricted use, distribution, and reproduction in any medium, provided you give appropriate credit to the original author(s) and the source, provide a link to the Creative Commons license, and indicate if changes were made.

\section{References}

Ahmadova N, Ho FM, Styring S, Mamedov F (2017) Tyrozine D oxidation and redox equilibrium in photosystem II. Biochim Biophys Acta 1858(6):407-417. doi:10.1016/j.bbabio.2017.02.011

Babcock GT, Sauer K (1973) Electron paramagnetic resonance signal II in spinach-chloroplast. 1. Kinetic analysis for untreated chloroplasts. Biochim Biophys Acta 325(3):483-503. doi:10.1016/0005-2728(73)90209-0

Babcock GT, Sauer K (1975a) A rapid, light-induced transient in electron paramagnetic resonance signal II activated upon inhibition of photosynthetic oxygen evolution. Biochim Biophys Acta 376(2):315-328. doi:10.1016/0005-2728(75)90024-9 
Babcock GT, Sauer K (1975b) Two electron donation sites for exogenous reductants in chloroplast photosystem II. Biochim Biophys Acta 396(1):48-62. doi:10.1016/0005-2728(75)90188-7

Barber J (2016) Photosystem II: the water splitting enzyme of photosynthesis and the origin of oxygen in our atmosphere. Quart Rev Biophys 49:1-20. doi:10.1017/s0033583516000093

Berthold DA, Babcock GT, Yocum CF (1981) A highly resolved, oxygen-evolving photosystem II preparation from spinach thylakoid membranes: EPR and electron-transport properties. Febs Lett 134(2):231-234. doi:10.1016/0014-5793(81)80608-4

Bishop NI, Spikes JD (1955) Inhibition by cyanide of the photochemical activity of isolated chloroplasts. Nature 176(4476):307-308

Boska M, Sauer K, Buttner W, Babcock GT (1983) Similarity of electron paramagnetic resonance Signal IIf rise and $\mathrm{P}_{680}{ }^{+}$decay kinetics in Tris-washed chloroplast photosystem II preparations as a function of $\mathrm{pH}$. Biochim Biophys Acta 722(2):327-330. doi:10.1016/0005-2728(83)90080-4

Boussac A, Etienne A-L (1982a) Spectral and kinetic pH-dependence of fast and slow signal II in tris-washed chloroplasts. FEBS Lett 148(1):113-116. doi:10.1016/0014-5793(82)81254-4

Boussac A, Etienne AL (1982b) Heterogeneity of system II secondary electron acceptors in tris-washed chloroplasts. Biochim Biophys Acta 682(2):281-288. doi:10.1016/0005-2728(82)90109-8

Boussac A, Etienne AL (1982c) Oxido-reduction kinetics of signal II slow in tris-washed chloroplasts. Biochem Biophys Res Commun 109(4):1200-1205. doi:10.1016/0006-291x(82)91904-0

Boussac A, Etienne AL (1984) Midpoint potential of signal II (slow) in tris-washed photosystem-II particles. Biochim Biophys Acta 766(3):576-581. doi:10.1016/0005-2728(84)90117-8

Brettel K, Schlodder E, Witt HT (1984) Nanosecond reduction kinetics of photooxidized chlorophyll-aII (P-680) in single flashes as a probe for the electron pathway, $\mathrm{H}^{+}$-release and charge accumulation in the $\mathrm{O}_{2}$-evolving complex. Biochim Biophys Acta 766(2):403-415. doi:10.1016/0005-2728(84)90256-1

Bricker TM, Roose JL, Fagerlund RD, Frankel LK, Eaton-Rye JJ (2012) The extrinsic proteins of photosystem II. Biochim Biophys Acta 1817(1):121-142. doi:10.1016/j.bbabio.2011.07.006

Buser CA, Thompson LK, Diner BA, Brudvig GW (1990) Electron transfer reactions in manganese-depleted Photosystem II. Biochemistry 29:8977-8985

Cardona T, Sedoud A, Cox N, Rutherford AW (2012) Charge separation in photosystem II: a comparative and evolutionary overview. Biochim Biophys Acta 1817(1):26-43. doi:10.1016/j. bbabio.2011.07.012

Danielsson R, Suorsa M, Paakkarinen V, Albertsson PA, Styring S, Aro EM, Mamedov F (2006) Dimeric and monomeric organization of photosystem II - Distribution of five distinct complexes in the different domains of the thylakoid membrane. J Biol Chem 281(20):14241-14249. doi:10.1074/jbc.M600634200

Debus RJ, Barry BA, Babcock GT, McIntosh L (1988) Site-directed mutagenesis identifies a tyrosine radical involved in the photosynthetic oxygen-evolving system. Proc Natl Acad Sci USA 85(2):427-430

Delrieu M-J, Rosengard F (1989) Interaction of erogenous quinones with photosystem II in inside-out thylakoids. FEBS Lett 251(1):161-166. doi:10.1016/0014-5793(89)81447-4

Diner BA, Rappaport F (2002) Structure, dynamics, and energetics of the primary photochemistry of photosystem II of oxygenic photosynthesis. Annu Rev Plant Biol 53:551-580. doi:10.1146/annurev. arplant.53.100301.135238

Diner BA, Schlodder E, Nixon PJ, Coleman WJ, Rappaport F, Lavergne J, Vermaas WFJ, Chisholm DA (2001) Site-directed mutations at D1-His 198 and D2-His197 of photosystem II in synechocystis PCC 6803: sites of primary charge separation and cation and triplet stabilization. Biochemistry 40(31):9265-9281. doi:10.1021/ bi010121r
Faller P, Debus RJ, Brettel K, Sugiura M, Rutherford AW, Boussac A (2001) Rapid formation of the stable tyrosyl radical in photosystem II. Proc Natl Acad Sci USA 98(25):14368-14373. doi:10.1073/pnas.251382598

Faller P, Rutherford AW, Debus RJ (2002) Tyrosine D oxidation at cryogenic temperature in photosystem II. Biochemistry 41(43):12914-12920. doi:10.1021/bi026588z

Ferreira KN, Iverson TM, Maghlaoui K, Barber J, Iwata S (2004) Architecture of the photosynthetic oxygen-evolving center. Science 303(5665):1831-1838. doi:10.1126/science.1093087

Gadjieva R, Mamedov F, Renger G, Styring S (1999) Interconversion of low- and high-potential forms of cytochrome b(559) in triswashed photosystem II membranes under aerobic and anaerobic conditions. Biochemistry 38(32):10578-10584. doi:10.1021/ bi9904656

Grabolle M, Dau H (2005) Energetics of primary and secondary electron transfer in photosystem II membrane particles of spinach revisited on basis of recombination-fluorescence measurements. Biochim Biophys Acta 1708(2):209-218. doi:10.1016/j. bbabio.2005.03.007

Groot ML, Pawlowicz NP, van Wilderen LJGW, Breton J, van Stokkum IHM, van Grondelle R (2005) Initial electron donor and acceptor in isolated photosystem II reaction centers identified with femtosecond mid-IR spectroscopy. Proc Natl Acad Sci USA 102(37):13087-13092. doi:10.1073/pnas.0503483102

Hanley J, Deligiannakis Y, Pascal A, Faller P, Rutherford AW (1999) Carotenoid oxidation in photosystem II. Biochemistry 38(26):8189-8195. doi:10.1021/bi990633u

Hillmann B, Brettel K, van Mieghem F, Kamlowski A, Rutherford AW, Schlodder E (1995) Charge recombination reactions in photosystem II. 2. Transient absorbance difference spectra and their temperature dependence. Biochemistry 34(14):4814-4827. doi: $10.1021 / \mathrm{bi00014a039}$

Holzwarth AR, Müller MG, Reus M, Nowaczyk M, Sander J, Rögner M (2006) Kinetics and mechanism of electron transfer in intact photosystem II and in the isolated reaction center: Pheophytin is the primary electron acceptor. Proc Natl Acad Sci 103(18):68956900. doi:10.1073/pnas.0505371103

Hughes JL, Smith P, Pace R, Krausz E (2006) Charge separation in photosystem II core complexes induced by $690-730 \mathrm{~nm}$ excitation at $1.7 \mathrm{~K}$. Biochim Biophys Acta 1757(7):841-851. doi:10.1016/j. bbabio.2006.05.035

Kern J, Renger G (2007) Photosystem II: structure and mechanism of the water: plastoquinone oxidoreductase. Photosyn Res 94(23):183-202. doi:10.1007/s11120-007-9201-1

Mamedov F, Gadjieva R, Styring S (2007) Oxygen-induced changes in the redox state of the cytochrome b559 in photosystem II depend on the integrity of the Mn cluster. Physiol Plant 131(1):41-49

Mokvist F, Sjöholm J, Mamedov F, Styring S (2014) The photochemistry in photosystem II at $5 \mathrm{~K}$ is different in visible and far-red light. Biochemistry 53(26):4228-4238. doi:10.1021/bi5006392

Novoderezhkin VI, Croce R, Wahadoszamen M, Polukhina I, Romero E, van Grondelle R (2016) Mixing of exciton and charge-transfer states in light-harvesting complex Lhca4. Phys Chem Chem Phys 18(28):19368-19377. doi:10.1039/C6CP02225A

Rappaport F, Diner BA (2008) Primary photochemistry and energetics leading to the oxidation of the (Mn)4Ca cluster and to the evolution of molecular oxygen in photosystem II. Coord Chem Rev 252(3-4):259-272. doi:10.1016/j.ccr.2007.07.016

Rappaport F, Guergova-Kuras M, Nixon PJ, Diner BA, Lavergne J (2002) Kinetics and pathways of charge recombination in photosystem II. Biochemistry 41:8518-8527

Raszewski G, Saenger W, Renger T (2005) Theory of optical spectra of photosystem II reaction centers: location of the triplet state and the identity of the primary electron donor. Biophys J 88(2):986998. doi:10.1529/biophysj.104.050294 
Raszewski G, Diner BA, Schlodder E, Renger T (2008) Spectroscopic properties of reaction center pigments in photosystem II core complexes: revision of the multimer model. Biophys J 95(1):105-119. doi:10.1529/biophysj.107.123935

Renger G (2012) Mechanism of light induced water splitting in photosystem II of oxygen evolving photosynthetic organisms. Biochim Biophys Acta 1817(8):1164-1176. doi:10.1016/j. bbabio.2012.02.005

Reimers JR, Biczysko M, Bruce D, Coker DF, Frankcombe TJ, Hashimoto H, Hauer J, Jankowiak R, Kramer T, Linnanto J, Mamedov F, Müh F, Rätsep M, Renger T, Styring S, Wan J, Wang Z, WangOtomo Z-Y, Weng Y-X, Yang C, Zhang J-P, Freiberg A, Krausz E (2016) Challenges facing an understanding of the nature of lowenergy excited states in photosynthesis. Biochim Biophys Acta 1857(9):1627-1640

Renger G, Renger T (2008) Photosystem II: the machinery of photosynthetic water splitting. Photosynth Res 98(1-3):53-80. doi:10.1007/s11120-008-9345-7

Roffey RA, van Wijk KJ, Sayre RT, Styring S (1994) Spectroscopic characterization of tyrosine-Z in histidine 190 mutants of the D1 protein in photosystem II (PS II) in Chlamydomonas reinhardtii. Implications for the structural model of the donor side of PS II. J Biol Chem 269(7):5115-5121

Romero E, van Stokkum IHM, Novoderezhkin VI, Dekker JP, van Grondelle R (2010) Two different charge separation pathways in photosystem II. Biochemistry 49(20):4300-4307. doi:10.1021/ bi1003926

Romero E, Diner BA, Nixon PJ, Coleman WJ, Dekker JP, van Grondelle R (2012) Mixed exciton-charge-transfer states in photosystem II: stark spectroscopy on site-directed mutants. Biophys J 103(2):185-194. doi:10.1016/j.bpj.2012.06.026

Saito K, Rutherford AW, Ishikita H (2013) Mechanism of tyrosine D oxidation in photosystem II. Proc Natl Acad Sci USA 110(19):7690-7695. doi:10.1073/pnas.1300817110

Schlodder E, Coleman WJ, Nixon PJ, Cohen RO, Renger T, Diner BA (2008a) Site-directed mutations at D1-His198 and D1-Thr179 of photosystem II in Synechocystis sp. PCC 6803: deciphering the spectral properties of the PS II reaction centre. Philos Trans 363(1494):1197-1202

Schlodder E, Renger T, Raszewski G, Coleman WJ, Nixon PJ, Cohen RO, Diner BA (2008b) Site-directed mutations at D1-Thr179 of photosystem II in Synechocystis sp. PCC 6803 modify the spectroscopic properties of the accessory chlorophyll in the D1-branch of the reaction center. Biochemistry 47(10):3143-3154. doi:10.1021/ bi702059f

Shigemori K, Mino H, Kawamori A (1997) pH and temperature dependence of tyrosine $Z$ " decay kinetics in tris-treated PS II particles studied by time-resolved EPR. Plant Cell Physiol 38(9):10071011. doi:10.1093/oxfordjournals.pcp.a029264
Sjöholm J, Ho FM, Ahmadova N, Brinkert K, Hammarström L, Mamedov F, Styring S (2016) The protonation state around TyrD/TyrD in photosystem II is reflected in its biphasic oxidation kinetics. Biochim Biophys Acta 1858:147-155

Styring S, Rutherford AW (1987) In the oxygen evolving complex of photosystem II the S0 state is oxidized to the S1 state by D+ (signal II slow). Biochemistry 26(9):2401-2405. doi:10.1021/ bi00383a001

Styring S, Sjöholm J, Mamedov F (2012) Two tyrosines that changed the world: interfacing the oxidizing power of photochemistry to water splitting in photosystem II. Biochim Biophys Acta 1817:76-87

Suga M, Akita F, Hirata K, Ueno G, Murakami H, Nakajima Y, Shimizu T, Yamashita K, Yamamoto M, Ago H, Shen JR (2015) Native structure of photosystem II at $1.95 \AA$ resolution viewed by femtosecond X-ray pulses. Nature 517(7532):99-U265. doi:10.1038/nature13991

Thapper A, Mamedov F, Mokvist F, Hammarström L, Styring S (2009) Defining the far-red limit of photosystem II in spinach. Plant Cell 21(8):2391-2401. doi:10.1105/tpc.108.064154

Umena Y, Kawakami K, Shen JR, Kamiya N (2011) Crystal structure of oxygen-evolving photosystem II at a resolution of $1.9 \AA$ A. Nature 473(7345):55-U65. doi:10.1038/nature09913

Vass I, Styring S (1991) pH-dependent charge equilibria between tyrosine-D and the S states in photosystem II. Estimation of relative midpoint redox potentials. Biochemistry 30:830-839

Vinyard DJ, Ananyev GM, Dismukes GC (2013) Photosystem II: the reaction center of oxygenic photosynthesis. In: Kornberg RD (ed) Annual review of biochemistry, vol 82. Annual Reviews, Palo Alto, pp 577-606. doi:10.1146/annurev-biochem-070511-100425

Visser JWM, Rijgersberg CP, Gast P (1977) Photooxidation of chlorophyll in spinach chloroplasts between 10 and $180 \mathrm{~K}$. Biochim Biophys Acta 460(1):36-46. doi:10.1016/0005-2728(77)90149-9

Völker M, Ono T, Inoue Y, Renger G (1985) Effect of trypsin on PSII particles: correlation between Hill-activity, Mn-abundance and peptide pattern. Biochim Biophys Acta 806:25-34

Wei X, Su X, Cao P, Liu X, Chang W, Li M, Zhang X, Liu Z (2016) Structure of spinach photosystem II-LHCII supercomplex at $3.2 \AA$ resolution. Nature 534 (7605):69-74. doi:10.1038/ nature18020. http://www.nature.com/nature/journal/v534/n7605/ abs/nature 18020.html\#supplementary-information

Yerkes CT, Babcock GT (1980) Photosystem II oxidation of charged electron donors. Surface charge effects. Biochim Biophys Acta 590(3):360-372. doi:10.1016/0005-2728(80)90207-8

Zech SG, Kurreck J, Eckert H-J, Renger G, Lubitz W, Bittl R (1997) Pulsed EPR measurement of the distance between $\mathrm{P}_{680}{ }^{+}$and $\mathrm{QA}^{-}$in photosystem II. FEBS Lett 414(2):454-456. doi:10.1016/ S0014-5793(97)01054-5 